\title{
Clusterin secreted from astrocyte promotes excitatory synaptic transmission and ameliorates Alzheimer's disease neuropathology
}

\author{
Fading Chen ${ }^{1,2}$, Dan B. Swartzlander ${ }^{1}$, Anamitra Ghosh ${ }^{1}$, John D. Fryer ${ }^{3}$, Baiping Wang ${ }^{1,4^{*}}$ and Hui Zheng ${ }^{1,4^{*}}$ (D)
}

\begin{abstract}
Background: Genome-wide association studies have established clusterin (CLU) as a genetic modifier for late-onset Alzheimer's disease (AD). Both protective and risk alleles have been identified which may be associated with its expression levels. However, the physiological function of clusterin in the central nervous system remains largely unknown.

Methods: We examined Clu expression in mouse brains by immunohistochemistry and high-resolution imaging. We performed electrophysiological recordings and morphological analysis of dendritic spines in wild-type and Clu knockout mice. We tested synaptic function of astrocytic Clu using neuron-glia co-cultures and by AAV-mediated astroglial Clu expression in vivo. Finally, we investigated the role of astrocytic Clu on synaptic properties and amyloid pathology in 5xFAD transgenic mouse model of AD.

Results: We show that astrocyte secreted Clu co-localizes with presynaptic puncta of excitatory neurons. Loss of Clu led to impaired presynaptic function and reduced spine density in vivo. Neurons co-cultured with Cluoverexpressing astrocytes or treated with conditioned media from HEK293 cells transfected with Clu displayed enhanced excitatory neurotransmission. AAV-mediated astroglial Clu expression promoted excitatory neurotransmission in wild-type mice and rescued synaptic deficits in Clu knockout mice. Overexpression of Clu in the astrocytes of 5xFAD mice led to reduced $A \beta$ pathology and fully rescued the synaptic deficits.

Conclusion: We identify Clu as an astrocyte-derived synaptogenic and anti-amyloid factor; the combination of these activities may influence the progression of late-onset $\mathrm{AD}$.
\end{abstract}

Keywords: Alzheimer's disease, Amyloid, Astrocyte, Clusterin, Mice, Synaptic transmission

\section{Introduction}

Alzheimer's disease (AD) is a neurodegenerative disease characterized by progressive deterioration of memory and cognitive function, the accumulation of $\beta$-amyloid $(\mathrm{A} \beta)$ plaques and neurofibrillary tangles and synaptic

\footnotetext{
* Correspondence: baipingw@bcm.edu; huiz@bcm.edu

'Huffington Center on Aging, Baylor College of Medicine, Houston, TX 77030, USA

Full list of author information is available at the end of the article
}

and neuronal loss leading to dementia. Synapse degeneration is widely accepted as an early and causal event in $\mathrm{AD}$ pathogenesis [1]. While genetic studies have discovered rare mutations in genes (APP, PSEN1 and PSEN2) that cause familial early-onset $\mathrm{AD}$ [2], the vast majority of $\mathrm{AD}$ cases are late-onset (LOAD) influenced by a large number of low-penetrant alleles that may either increase or reduce the risk. Clusterin ( $C L U$; also known as apolipoprotein J or ApoJ) was identified by two independent

C C The Author(s). 2021 Open Access This article is licensed under a Creative Commons Attribution 4.0 International License, which permits use, sharing, adaptation, distribution and reproduction in any medium or format, as long as you give appropriate credit to the original author(s) and the source, provide a link to the Creative Commons licence, and indicate if changes were made. The images or other third party material in this article are included in the article's Creative Commons licence, unless indicated otherwise in a credit line to the material. If material is not included in the article's Creative Commons licence and your intended use is not permitted by statutory regulation or exceeds the permitted use, you will need to obtain permission directly from the copyright holder. To view a copy of this licence, visit http://creativecommons.org/licenses/by/4.0/ The Creative Commons Public Domain Dedication waiver (http://creativecommons.org/publicdomain/zero/1.0/) applies to the data made available in this article, unless otherwise stated in a credit line to the data. 
genome-wide association studies as one of the most significant LOAD genes $[3,4]$. Subsequent studies revealed that the major $\mathrm{rs} 11136000^{\mathrm{C}}$ allele confers an increased risk for $\mathrm{AD}$ and is associated with reduced $C L U$ expression whereas the minor $\mathrm{rs} 11136000^{\mathrm{T}}$ allele is associated with increased $C L U$ expression and reduced AD risk [5-8]. The $\mathrm{C}$ allele is also associated with faster cognitive decline in presymptomatic stages of $\mathrm{AD}$ [9], poorer memory scores in both $\mathrm{AD}$ and non-demented elderly [10], as well as altered brain structure and circuit activity in young healthy adults $[11,12]$, suggesting that changes of neural network early in life may affect cognitive function and $A D$ progression at later stages in $\mathrm{C}$ allele carrying individuals. A better understanding of CLU's function, particularly in synaptic regulation, may thus provide mechanistic insight into its genetic association in LOAD.

CLU is a multifunctional protein that can be present intracellularly or secreted as lipoprotein particles [13]. In the peripheral system, CLU is known to participate in a variety of cellular processes, ranging from extracellular misfolded protein clearance [14], lipid transport [13], complement inhibition [15], to oxidative stress and cell death [16]. CLU is highly expressed in the brain but its physiological function in the central nervous system is poorly understood. Elevated levels of CLU have been observed in brain tissues and cerebrospinal fluid (CSF) of $\mathrm{AD}$ patients [17-20]. However, the molecular underpinning and functional consequences of this increase is not clear. It is known that CLU is present in the $A \beta$ plaques and in vessels of cerebral amyloid angiopathy (CAA) [21-23]. As an extracellular chaperone, CLU has been shown to bind to $A \beta$ and is involved in $A \beta$ deposition, fibrillogenesis, and clearance $[24,25]$. In vivo studies using APP transgenic mice crossed with $\mathrm{Clu}$ knockout mice revealed that loss of Clu leads to reduced dense core plaques and heightened CAA [26, 27], demonstrating an important role of $\mathrm{Clu}$ in modulating both $A \beta$ deposition in the brain and its clearance through the blood brain barrier. Nevertheless, since CLU is upregulated in AD conditions, how CLU overexpression affects $\mathrm{AD}$ pathophysiology in vivo is a critical question remains to be addressed.

Here we utilized $\mathrm{Clu}$ knockout mice and AAVmediated gene delivery to drive the expression of $\mathrm{Clu}$ in astrocytes of WT and 5xFAD mice and investigated the role of Clu in synaptic transmission and amyloid pathology. We demonstrate that Clu secreted from astrocyte is required for proper excitatory synaptic transmission and spine density under physiological conditions and attenuates amyloid pathology and associated neuronal toxicity in an AD mouse model.

\section{Methods}

\section{Mice and AAV delivery}

The Aldh1L1-GFP [28], Clu knockout [29], Thy1-EGFP [30], and 5XFAD mice [31] have been described previously. The mice were obtained from the Jackson Laboratory (Bar Harbor, ME, USA) and have been backcrossed to $\mathrm{C} 57 \mathrm{BL} / 6$ background for at least ten generations. Both female and male mice were used unless otherwise specified. For AAV-mediated gene delivery, P3 pups were anesthetized via hypothermia and injected freehand into the bilateral ventricles with $5 \times 10^{10}$ viral particles per side of AAV2/8-GFAP-GFP or AAV2/8-GFAPClu using a 28-gauge needle attached to a Hamilton syringe.

All experiments were performed in accordance with procedures approved by the Institutional Animal Care and Use Committee of Baylor College of Medicine and ARRIVE guidelines.

\section{Clu conditioned medium (CM) preparation}

Clu CM was collected from cultured HEK293 cells. Briefly, 90\% confluent HEK293 cells were transfected with plasmid containing mouse Clu cDNA or empty vector (Origene) using Lipofectamine 3000 (Invitrogen) following the manufacturer's instructions. Two days after transfection, the cells were washed with warm DPBS and placed in minimum medium containing phenol red-free Neurobasal, glutamax and Pen/Strep for 3 days. The medium was collected, concentrated 30-50 folds using centrifugal filter (Millipore, MWCO $10 \mathrm{~K}$ ), and applied to primary cultured neurons at $30-40 \mu \mathrm{g} /$ $\mathrm{ml}$.

\section{Primary neuronal culture}

Dissociated cortical neurons were harvested from P0 mice. Briefly, newborn pups were decapitated and dissected in ice-cold dissection medium (HBSS with 10 $\mathrm{mM}$ HEPES, $0.6 \%$ glucose, $1 \% \mathrm{v} / \mathrm{v}$ Pen/Strep). Dissected mouse cortex was cut into small pieces, followed by enzymatic digestion using papain dissociation system (Worthington Biochemical Corporation) according to manufacturer's instructions. Dissociated neurons were cultured on glass coverslips coated with poly-D-lysine (PDL) and laminin at a density of 200,000 cells $/ \mathrm{cm}^{2}$. Neuronal culture media consisted of Neurobasal medium supplemented with 1x Glutamax, $1000 \mu / \mathrm{ml}$ Pen/Strep, 1x B27 supplement. Cultures were maintained at $37^{\circ} \mathrm{C}$ in $5 \%$ ambient $\mathrm{CO}_{2}$. Half medium was changed every other day.

\section{Primary astrocyte culture}

Mouse cortex was isolated from P3 pups for astrocyte culture. Briefly, the brain was dissected in ice-cold dissection medium (HBSS with $10 \mathrm{mM}$ HEPES, 0.6\% 
glucose, $1 \% \mathrm{v} / \mathrm{v}$ Pen/Strep) and finely minced. The tissue was digested in $2.5 \%$ trypsin at $37^{\circ} \mathrm{C}$ for $15 \mathrm{~min}$, followed by the addition of trypsin inhibitor $(1 \mathrm{mg} / \mathrm{ml})$ and DNase. The tissue was then centrifuged at $1000 \mathrm{~g}$ for $5 \mathrm{~min}$, triturated, re-suspended in astrocyte culture medium (DMEM + 10\% FBS $+1000 \mu / \mathrm{ml} \mathrm{Pen/Strep).}$ Cells were plated on PDL coated T75 flasks at 50,000 cells $/ \mathrm{cm}^{2}$. After the culture reached confluency, the flasks were rocked at $250 \mathrm{rpm}$ overnight at $37^{\circ} \mathrm{C}$ to remove unwanted cell types (microglia, oligodendrocytes, neurons, and fibroblasts). After recovery in fresh medium for $24 \mathrm{~h}$, astrocytes were trypsinized in $0.25 \%$ trypsin/EDTA and re-plated on PDL coated glass coverslip for future experiments.

\section{Primary astrocyte AAV transduction and neuron-astrocyte co-culture}

For AAV transduction in primary astrocytes, the viral particles were added to the reduced serum medium (DMEM + 2\% FBS) at 500,000 multiplicity of infection in half of the usual volume. Following 4-6h of incubation, equal amount of fresh astrocyte medium (DMEM $+10 \%$ FBS) was added to the culture. The medium was changed 2 days later. Astrocytes were cultured for an additional 2 weeks to reach optimal Clu or GFP expression. Transduction efficiency was observed at $>90 \%$.

Primary cortical neurons harvested from P0 pups were seeded on top of transduced astrocyte monolayer to form neuron-astrocyte co-culture. The co-culture was maintained in the neuronal culture media. Half of the medium was replaced with fresh medium every other day.

\section{Immunoblotting}

For Western blot, cells and brain tissues were lysed in RIPA buffer (TBS with 1\% NP-40, 1\% sodium deoxycholic acid, $0.1 \%$ sodium dodecyl sulfate, and protease/ phosphatase inhibitor cocktails). Lysates were sonicated (six pulses at $50 \%$ duty cycle) and incubated on ice for $30 \mathrm{~min}$. Samples were then centrifuged at $20,000 \mathrm{~g}$ for $20 \mathrm{~min}$. Supernatants were collected and quantified using a Pierce BCA Protein Assay kit (Thermo Fisher). $20-\mu$ g protein samples were loaded onto $12 \%$ SDS-PAGE gels and then transferred to nitrocellulose membranes (Bio-Rad). Membranes were blocked in $5 \%$ nonfat milk in PBST (PBS $+0.1 \%$ Tween 20 ). Blots were probed with primary antibodies overnight at $4{ }^{\circ} \mathrm{C}$. After washing with PBST, blots were then probed with a donkey anti-goat $\operatorname{IgG}(\mathrm{H}+\mathrm{L})$ conjugated to IRDye $800 \mathrm{CW}$ (LI-COR) secondary antibody. The signals were detected on the LI-COR Odyssey (LI-COR, Bad Homburg, Germany).

\section{Immunofluorescence staining}

Animals were perfused transcardially with $4 \%$ paraformaldehyde (PFA) in $0.1 \mathrm{M}$ phosphate-buffered saline (PBS), $\mathrm{pH} 7.4$, under ketamine $(300 \mathrm{mg} / \mathrm{kg})$ and xylazine $(30 \mathrm{mg} / \mathrm{kg}$ ) anesthesia. Brains were harvested, post-fixed in the same fixative overnight at $4{ }^{\circ} \mathrm{C}$, dehydrated with $30 \%$ sucrose in PBS, and serially sectioned at $40 \mu \mathrm{m}$ on a sliding microtome (Leica). For immunofluorescence, sections were permeabilized in PBS/0.1\% Triton X-100 for 10 min and blocked with $4 \%$ normal goat serum in PBS/ $0.1 \%$ Triton X-100 for $1 \mathrm{~h}$ at room temperature. Sections were then incubated with primary antibodies in $2 \%$ serum in $\mathrm{PBS} / 0.1 \%$ Triton $\mathrm{X}-100$ overnight at $4{ }^{\circ} \mathrm{C}$ : GFAP (1:1000, EMD Millipore); Iba-1 (1:800, Wako); Clu (1:1000, R\&D systems); vGlut1 (1:1000, AbCam); GAD67 (1:1000, Millipore); PSD-95 (1:1000, BD Transduction Laboratories); 6E10 (1:1000, BioLegend); CD68 (1:500, BioLegend). Sections were then washed and incubated with Alexa Fluor 594- or Alexa Fluor 647conjugated secondary antibodies (Invitrogen) for $1 \mathrm{~h}$ at room temperature. After washing with PBS, sections were incubated with either DAPI to stain the nucleus or methoxy-X04 (Tocris) to stain the $A \beta$ plaques. Images were captured using a Laser-Scanning Confocal Microscopy (Leica).

\section{Quantitative analyses of dendritic spines}

Four-month-old Thy1-GFP mice on wild-type or Clu KO background were perfused. Brain slides were individually coded and randomly ordered for image acquisition. High-resolution images of tertiary and quaternary branches of apical dendrites of pyramidal neurons (3-5 randomly selected neurons per mouse $/ 4$ mice per group), displaying GFP fluorescence throughout the entire dendritic tree, were acquired using a Leica laserscanning confocal microscopes with oil immersion at $63 \times$ (NA 1.4) objective and $5 \times$ digital zoom. Series of optical sections were acquired in the z-axis at $0.08 \mu \mathrm{m}$ intervals through individual apical dendritic branches. The dendritic fragments and spines were traced and the classification and quantification of spine types were performed by the 3-D IMARIS software. Spine density was calculated by quantifying the number of spines per $10 \mu \mathrm{m}$ of dendritic segment.

\section{Transcriptome and gene ontology analysis}

The NanoString nCounter Analysis system was used to analyze the total RNA extracted from neuronal cultures. Normalization and calculation of differential expression was performed using nSolver 4.0 with default settings (NanoString Platform, NanoString Technologies). Gene clusters were analyzed using protein analysis through evolutionary relationships (PANTHER) Overrepresentation Test based on the gene ontology (GO) database 
(http://www.pantherdb.org/). Reactome pathway analysis (https://reactome.org/) was used to determine the enriched pathways of top expressed genes.

\section{Electrophysiology}

Briefly, mice were anesthetized and perfused with icecold sucrose-based cutting solution (250 mM Sucrose, $2.5 \mathrm{mM} \mathrm{KCl}, 1.25 \mathrm{mM} \mathrm{NaH}_{2} \mathrm{PO}_{4}, 25 \mathrm{mM} \mathrm{NaHCO}, 10$ $\mathrm{mM} \mathrm{MgCl}, 1 \mathrm{mM} \mathrm{CaCl}$, and $10 \mathrm{mM}$ glucose, saturated with $95 \% \mathrm{O}_{2}$ and $\left.5 \% \mathrm{CO}_{2}\right) .350 \mu \mathrm{m}$ horizontal hippocampus sections were cut using a Leica VT1200S vibratome and slices were allowed to recover for at least $1 \mathrm{~h}$ in recording artificial cerebrospinal fluid (ACSF) (125 $\mathrm{mM} \mathrm{NaCl}, 2.5 \mathrm{mM} \mathrm{KCl}, 1.25 \mathrm{mM} \mathrm{NaH} \mathrm{PO}_{4}, 25 \mathrm{mM}$ $\mathrm{NaHCO}_{3}, 1 \mathrm{mM} \mathrm{MgCl}, 2 \mathrm{mM} \mathrm{CaCl}$, and $10 \mathrm{mM}$ glucose) bubbled with $95 \% \mathrm{O}_{2} / 5 \% \mathrm{CO}_{2}$ at all times to maintain consistent oxygenation and $\mathrm{pH}$. To record mEPSCs and mIPSC, pipettes were filled with a cesiumsubstituted intracellular solution $(\mathrm{mM}): 10 \mathrm{CsCl}, 105$ CsMeSO3, 0.5 ATP, 0.3 GTP, 10 Hepes, 5 glucose, 2 $\mathrm{MgCl} 2$ and 1 EGTA. For mEPSC recording, neurons were held at $-70 \mathrm{mV}$ in the present of $0.5 \mu \mathrm{M}$ TTX and $50 \mu \mathrm{M}$ Picrotoxin. For mIPSC recording, neurons were held at $10 \mathrm{mV}$ in the presence of $0.5 \mu \mathrm{M}$ TTX, $20 \mu \mathrm{M}$ DNQX and $50 \mu \mathrm{M}$ APV. Whole cell patch clamp recordings were acquired (MultiClamp 700B, Axon Instruments), digitized at $20 \mathrm{kHZ}$ (Digidata 1440A, Axon Instruments), filtered at $2 \mathrm{kHz}$, and acquired with pClamp software (Axon Instruments). Pipette resistance ranged from 4 to $7 \mathrm{M} \Omega$. Access resistance ranged from 8 to $20 \mathrm{M} \Omega$. Recordings were discarded if the initial leak current was above 200 pA or changed by more than $20 \%$ over the course of recording. Offline analysis was performed using Clampfit (Axon Instruments).

To record field excitatory postsynaptic potentials (fEPSPs), stimulation of Schaffer Collaterals from the CA3 region was performed with bipolar electrodes, while borosilicate glass capillary pipettes filled with recording ACSF (2-3.5 M $\Omega$ resistance) were used to record fEPSPs in the CA1 region. Signals were amplified using a MultiClamp 700B amplifier (Axon Instruments), digitized using a Digidata 1440A (Axon Instruments) with a 2 $\mathrm{kHz}$ low pass filter and a $3 \mathrm{~Hz}$ high pass filter and then captured and stored using Clampex 10.4 software (Axon Instruments) for offline data analysis using Clampfit (Axon Instruments).

\section{Statistical analysis}

All data were analyzed with GraphPad Prism v.7 and are presented as Mean \pm SEM $\left({ }^{*} p<0.05, * * p<0.01\right.$, and $* * * 0.001)$. Power analysis was performed using a confidence interval of $\alpha=0.05$. Pairwise comparisons were analyzed using two-tailed Student's t test. For multiple comparisons in fEPSP recording, ANOVA followed by Tukey's post hoc testing was used.

\section{Results \\ Clu is expressed in astrocytes and also targeted to the presynaptic sites}

We first examined the expression pattern of endogenous Clu using the Aldh1L1-GFP reporter mice [28]. Consistent with the previous reports [32, 33], immunostaining using an anti-Clu antibody showed that Clu is highly expressed in GFP-marked astrocytes that are also GFAP positive (Fig. 1a). In addition, high resolution confocal imaging detected $\mathrm{Clu}$ immunoreactivity as discrete synapse-like puncta outside astrocytes (Fig. 1b). Coimmunostaining with antibodies against the vesicular glutamate transporter (vGlut1) or GAD67, which marks presynaptic terminals of excitatory and inhibitory neurons, respectively, documented that $17.75 \%$ vGlut1positive puncta contained $\mathrm{Clu}$, whereas there was minimum co-localization between GAD67 and Clu (Fig. 1b). This result suggests that a fraction of $\mathrm{Clu}$ is targeted to the synaptic site where it is preferentially associated with glutamatergic synapses.

To distinguish whether the synaptic Clu puncta are secreted from astrocytes or they are neuronal derived, we delivered low dose AAV-GFAP-Clu virus to the lateral ventricles of $\mathrm{Clu}$ knockout (KO) mouse brains at postnatal day 3 (P3) to sparsely label astrocytes [34], and examined the expression pattern of the astroglial expressed AAV-Clu in the absence of neuronal Clu 28 days post infection. Co-immunostaining of $\mathrm{Clu}$ with GFAP observed prominent $\mathrm{Clu}$ expression in GFAP-positive astrocytes (Fig. 1c). Noticeably, Clu immunoreactivity filled the entire astrocyte territory in $\mathrm{Clu} \mathrm{KO}$ mouse, similar to the territory covered by GFP signals in AAVGFAP-GFP infected astrocyte (Fig. 1c). However, in contrast to the smooth GFP staining pattern, Clu immunostaining revealed discrete punctate pattern both inside and outside of astrocyte territory, demonstrating that these puncta are produced and secreted from infected astrocytes. Co-immunostaining of Clu with vGlut1 showed that, similar to endogenous $\mathrm{Clu}$, Clu secreted from infected astrocytes also co-localized with vGlut1 at the synaptic sites (Fig. 1d). Taking together, these data demonstrate that Clu secreted from astrocyte target to the presynaptic sites of excitatory neurons.

\section{Clu deficiency alters excitatory synaptic transmission and spine density in vivo}

The synaptic targeting supports a functional role of astrocytic $\mathrm{Clu}$ in excitatory synaptic transmission. To provide direct support, we performed ex vivo recordings of miniature excitatory and inhibitory postsynaptic currents (mEPSCs and mIPSCs) from hippocampal granule 


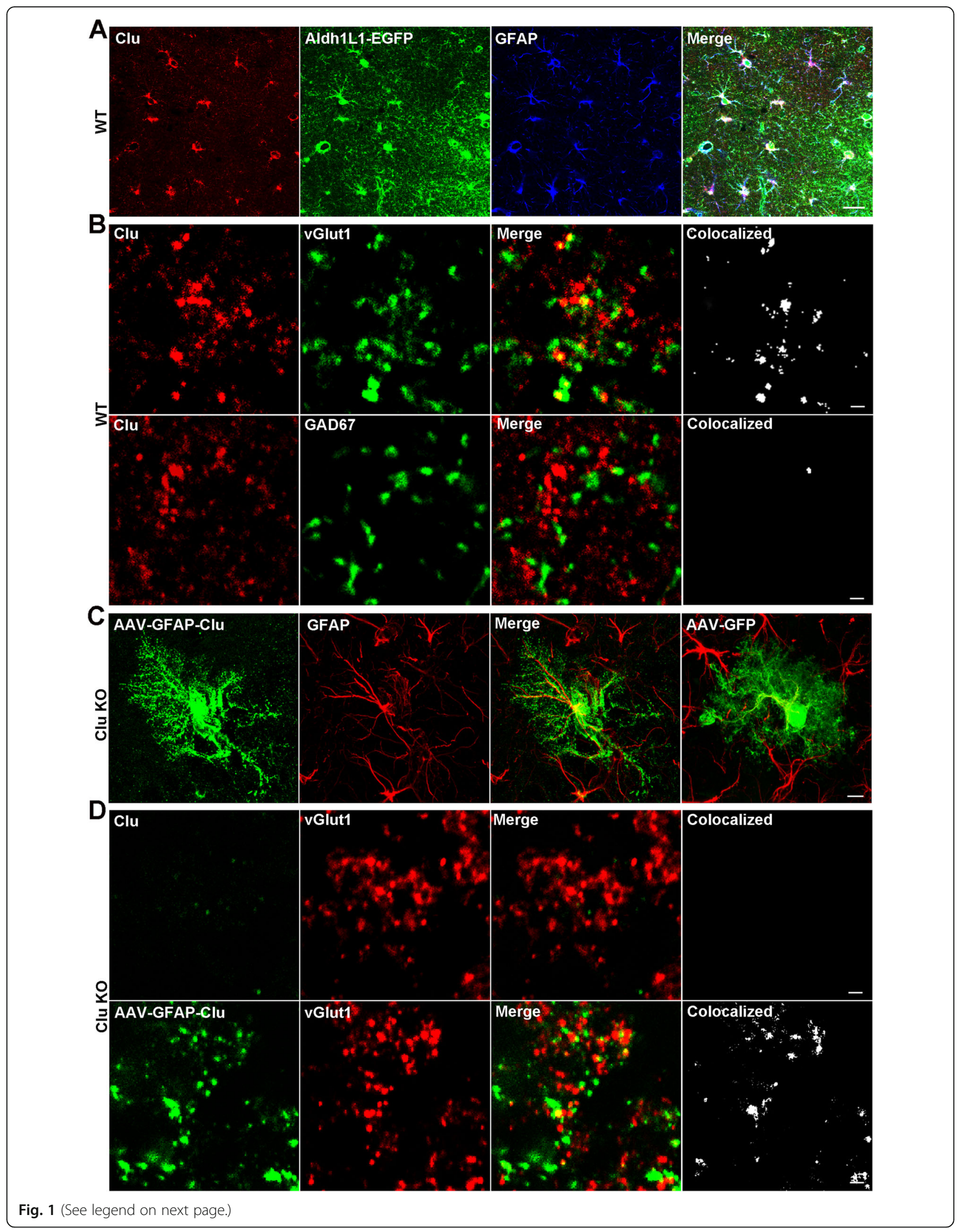


(See figure on previous page.)

Fig. $1 \mathrm{Clu}$ is expressed in astrocyte and targeted to the excitatory synaptic sites. a Immunofluorescence staining of hippocampal area CA1 of a Aldh1L1-EGFP mouse showing co-localization of endogenous Clu with EGFP-marked and GFAP-positive astrocytes. $\mathbf{b}$ Higher magnification confocal images showing abundant co-localization of Clu with excitatory synaptic structures marked by vGlut1 but not with inhibitory synapses marked by GAD67. c Immunofluorescence staining showing astroglial expression of Clu or GFP in Clu knockout mice 3 weeks after AAV-GFAP-Clu or AAV-GFAP-GFP infection. $\mathbf{d}$ Co-immunofluorescence staining of Clu and vGlut1 and high resolution confocal imaging of Clu KO mice infected with AAV-GFAP-Clu, showing co-localization of Clu puncta with vGlut1. Non-infected Clu KO (Clu) mice were used as controls. Scale bars, $20 \mu m$ (a), $5 \mu \mathrm{m}$ (c) and $1 \mu \mathrm{m}(\mathbf{b}) \&(\mathbf{d})$

neurons of P28-30 of Clu KO mice and their wild-type (WT) littermate controls. We observed a significant decrease of mEPSC frequency in $\mathrm{Clu} \mathrm{KO}$ neurons compared to WT controls as indicated by a right shift in cumulative probability of inter-event interval and a reduction in average frequency (Fig. 2a \& b), while both the cumulative probability and average mEPSC amplitude were comparable between WT and $\mathrm{Clu} \mathrm{KO}$ neurons (Fig. 2c). Neither the mIPSC frequency nor amplitude were altered in $\mathrm{Clu} \mathrm{KO}$ neurons compared to WT controls (Fig. 2d-f), suggesting that astrocytic Clu selectively regulates excitatory but not inhibitory synaptic transmission. The specific effect on mEPSC frequency but not amplitude indicates that Clu does not affect the postsynaptic response but rather acts by regulating presynaptic release probability and/or synapse density.

To probe the mechanisms further, we examined pathway-specific effect by recording field excitatory postsynaptic potentials (fEPSPs) of the Schaffer Collateral pathway of acute hippocampal slices. Compared with littermate WT controls, the slope of fEPSP plotted as a function of stimulus intensity was significantly lower in $\mathrm{Clu} \mathrm{KO}$ brain slices (Fig. 2g), indicating reduced total synaptic strength. To determine if this is due to alterations in presynaptic neurotransmitter release, we measured paired-pulse ratio (PPR), which is inversely related to probability of transmitter release, by recording fEPSPs evoked by two stimuli with various intervals. We detected significantly larger PPR in $\mathrm{Clu} \mathrm{KO}$ brain slices compared to WT controls (Fig. 2h), indicating that the probability of transmitter release is lower in $\mathrm{Clu} \mathrm{KO}$ hippocampus. These results suggest that $\mathrm{Clu}$ regulates excitatory synaptic transmission, at least in part, by modulating presynaptic release probability.

Since dendritic spines are the major sites of excitatory synaptic transmission, we analyzed spine density in $\mathrm{Clu}$ $\mathrm{KO}$ mice to determine whether there was an anatomical correlate to the reduced mEPSC frequency. We crossed the WT and Clu KO mice with a Thy1-GFP reporter [30], and analyzed the number of dendritic spines in sparsely labeled CA1 pyramidal neurons at 4 months of age. In addition, we performed $3 \mathrm{D}$ reconstruction of dendritic segments, followed by unbiased classification and quantification of spine types (Fig. 3a). We found significantly reduced total spine density in apical dendrites of Clu KO mice compared to WT controls (Fig. $3 \mathrm{~b})$. This was attributed by reductions of all spine types including stubby, mushroom, long-thin, and filopodia spines (Fig. 3c). The results combined demonstrate a physiological function of $\mathrm{Clu}$ in regulating excitatory synaptic transmission and spine density in vivo.

\section{Secreted Clu enhances excitatory neurotransmission in vitro}

We next employed in vitro systems to test whether $\mathrm{Clu}$ secreted from astrocytes can directly modulate synaptic transmission. We infected primary astrocyte cultures with either AAV-GFAP-GFP or AAV-GFAP-Clu and cocultured them with primary wild-type neurons. Western blot analysis of astrocyte conditioned media showed increased levels of mature, proteolytically cleaved, Clu proteins in AAV-GFAP-Clu infected cultures compared to GFP infected controls (Fig. 4a). After 12-14 days of coculture, we performed whole-cell voltage path clamping to record mEPSCs from cultured neurons. Primary neurons co-cultured with AAV-GFAP-Clu infected astrocytes displayed a significant increase of mEPSC frequency but normal amplitude compared with neurons co-cultured with astrocytes infected with control AAVGFAP-GFP virus (Fig. 4b-d).

To provide further evidence that secreted Clu modulates synaptic transmission, we overexpressed $\mathrm{Clu}$ in HEK293 cells and collected conditioned medium. Western blot analysis showed that both the full-length ( $>50$ $\mathrm{KDa}$ ) and cleaved bands can be detected in Clu transfected cell lysate, but secreted Clu is almost exclusively present as mature cleaved form (Fig. 4e). We applied the control or Clu expressing conditioned medium to cultured primary neurons at 8 days in vitro (DIV8), and performed whole cell voltage patch clamping to record mEPSCs at DIV12. Consistent with the co-culture data, neurons treated with Clu-expressing conditioned medium displayed a significantly increased mEPSC frequency but normal amplitude (Fig. 4f-h). Together these data demonstrate that secreted Clu positively regulates excitatory synaptic transmission.

Next we asked whether the increased mEPSC frequency is associated with higher synaptic density. We performed co-immunostaining of neurons treated with 
A

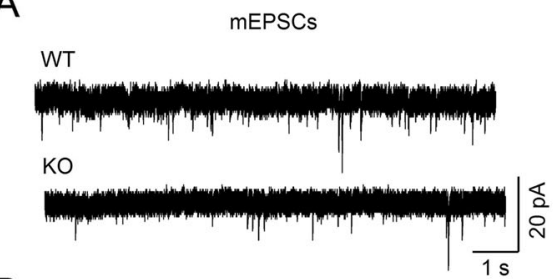

$\mathrm{B}$

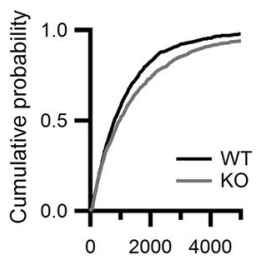

Inter-event Interval (ms)

C

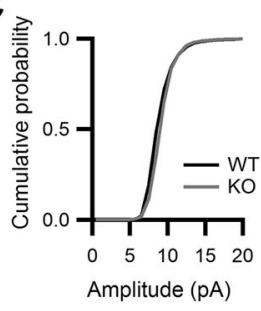

G
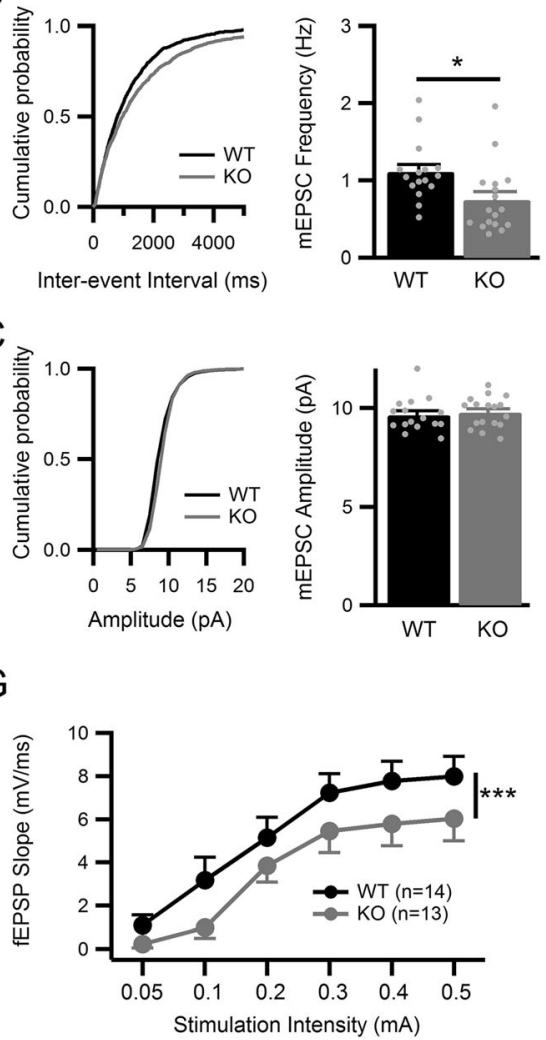

D

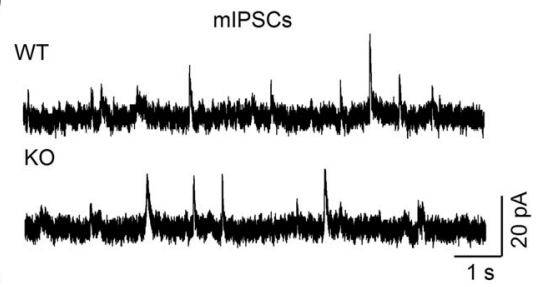

E

F
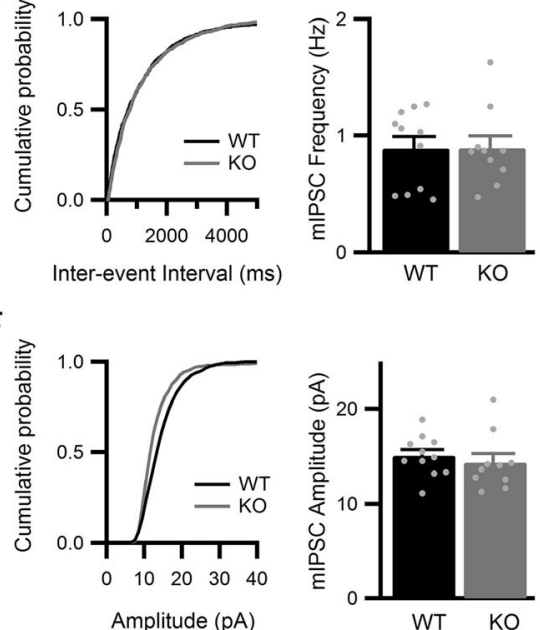

$\mathrm{H}$

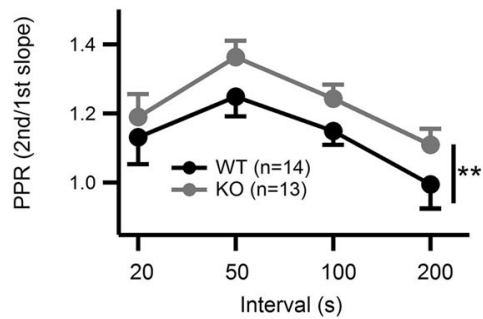

Fig. 2 Impaired excitatory neurotransmission in the hippocampus of Clu null mice. a mEPSC sample traces from WT and Clu KO neurons voltage clamped at $-65 \mathrm{mV}$ (scale bar, 20pA/2 s). b Cumulative distribution of inter-event interval from all mEPSCs events of $16 \mathrm{WT}$ and $17 \mathrm{KO}$ neurons (left) and average mEPSC frequency (right). c Cumulative distribution of amplitude of all neurons (left) and average mEPSC amplitude ( $n=16$ for WT and $n=17$ for KO). $\mathbf{d}$ mIPSC sample traces from WT and KO neurons voltage clamped at $10 \mathrm{mV}$ (scale bar, 20pA/2 s). e Cumulative distributions of inter-event interval from all mIPSCs events of $11 \mathrm{WT}$ and $10 \mathrm{KO}$ neurons (left) and average mIPSC frequency (right). f Cumulative distribution of amplitude of all neurons (left) and average mEPSC amplitude ( $n=11$ for WT and $n=10$ for KO). $\mathbf{g}$ Relationship between fEPSP slope and stimulating current intensity in WT and KO hippocampi showing a significant decrease in CA3-CA1 excitatory transmission $(n=14$ for both WT and KO). $\mathbf{h}$ Average paired pulse ratio (PPR) of fEPSP slope in CA3-CA1 synapse showing increased PPR in KO compared to WT ( $n=17$ for WT, $n=13$ for $\mathrm{KO}$ ). All data are presented as mean \pm SEM. Average number of animals tested: $N=3$ per group for whole cell recording and $N=4$ per group for field recording. ${ }^{*} p<0.05 ; * * p<0.01 ; * * * p<0.001$. Student's t-test $(\mathbf{b})$, (c), (e), (f); Two-way ANOVA (g) \& (h)

control or Clu medium with anti-vGlut1 and anti-PSD95 antibodies and quantified the number of co-localized puncta on MAP2-marked dendrites (Fig. 4i). Neurons treated with Clu-expressing conditioned medium displayed more synapses compared to the controls (Fig. $4 \mathrm{j}$ ), indicating that secreted Clu promotes excitatory synapse formation.

To provide molecular basis for the Clu-dependent effect, we performed gene expression profiling of primary neurons treated with control or Clu-expressing conditioned medium using the NanoString platform. We chose a predesigned neuropathology panel (770 genes) that contained the main neurotransmission and neuronglia interaction related pathways and detected 68 genes that were differentially expressed by $\mathrm{Clu}$ conditioned medium (Supplemental Table 1). Gene Ontology annotations identified the ionotropic metabotropic glutamate receptor pathway genes as the most overrepresented differentially expressed genes (Fig. 4k). To further explore the potential functional implications of these genes, we conducted pathway enrichment analysis based on the Reactome pathway database and found that pathways 


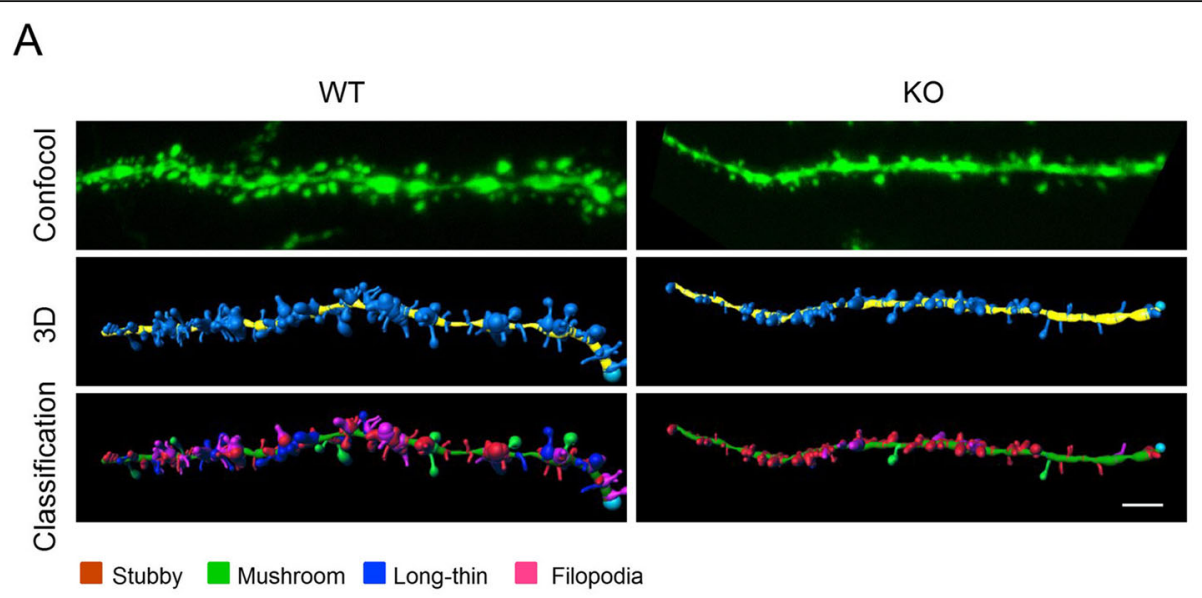

B

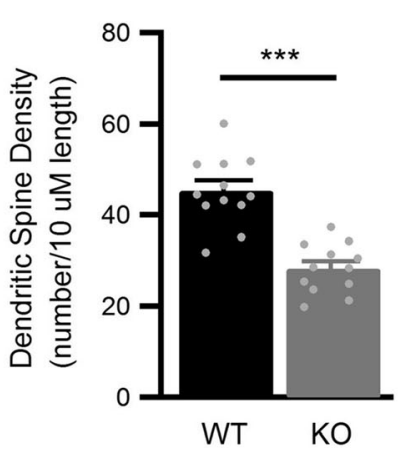

C

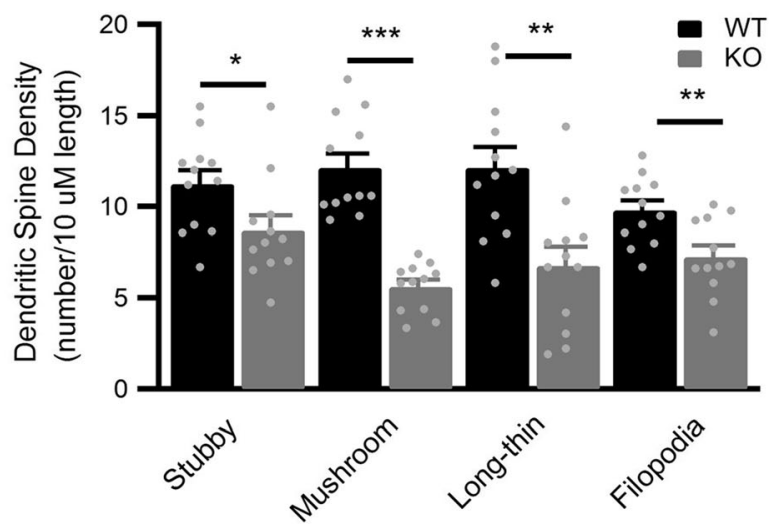

Fig. 3 Reduced dendritic spine density in hippocampal neurons of Clu KO mice. a Representative dendritic spines from Thy1-GFP-labeled dendrites in area CA1 of hippocampal pyramidal neurons of four-month-old littermate WT and Clu KO mouse brains. IMARIS was used to reconstruct the 3D rendering of the spines on dendrites based on confocal images of GFP-positive neurons and to classify the four spine types (mushroom, stubby, long-thin, and filopodia). Scale bar, $2 \mu \mathrm{m}$. b Total spine density in WT and Clu KO mouse brains. c Density of each of the four spine types on secondary apical dendrites of WT and Clu KO mouse brains. Dendritic segments were derived from 3 random neurons per mouse/ 4 animals for each group. All data are presented as mean \pm SEM. ${ }^{*} p<0.05 ; * * p<0.01 ; * * * p<0.001$ (Student's t test)

associated with synaptic transmission, axon guidance and protein-protein interactions at synapses were noticeably enriched (Table S1). All together, these results provide molecular, cellular and functional support that secreted $\mathrm{Clu}$ promotes synapse formation and glutamatergic synaptic function in vitro.

\section{Astrocytic Clu promotes excitatory neurotransmission in vivo and rescues synaptic deficits in Clu KO mice}

We proceeded to determine the role of astrocytic Clu in vivo by intraventricular injections of AAV-GFAP-Clu to P3 wild-type mouse brains [35]. AAV-GFAP-GFP injected mice were used as controls, which confirmed widespread and astrocyte-specific expressions in the brain (Supplementary Fig. S1). Western blot analysis showed significant increases of both full-length and cleaved Clu in AAV-GFAP-Clu injected mice (Fig. 5a). We harvested acute brain slices 4 weeks post injection and measured mEPSCs from hippocampal CA1 neurons. Consistent with our in vitro data, we observed that $\mathrm{Clu}$ overexpression in astrocytes significantly increased mEPSC frequency, but not amplitude (Fig. 5b-d), demonstrating that astrocyte derived $\mathrm{Clu}$ is sufficient to enhance excitatory neurotransmission in vivo.

We next injected AAV-GFAP-Clu to $\mathrm{Clu} \mathrm{KO}$ mice to evaluate whether astrocytic Clu expression can rescue the synaptic deficit in the mutant mice. Western blotting detected similar patterns of full-length and cleaved Clu in $\mathrm{Clu} \mathrm{KO}$ brain infected with AAV-GFAP-Clu compared to the wild-type mice (Fig. 6a). Measurement of excitatory synaptic strength by recording mEPSCs showed that, compared to GFP infected controls, astroglial Clu expression in $\mathrm{Clu} \mathrm{KO}$ mice significantly increased mEPSC frequency, but not amplitude, in CA1 pyramidal neurons (Fig. 6b-d). Additionally, we injected AAV-GFAP-Clu to $\mathrm{Clu}$ KO mice crossed with Thy1- 
A

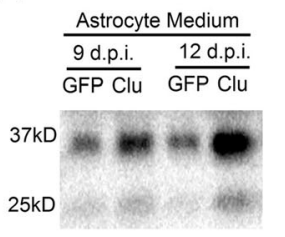

C

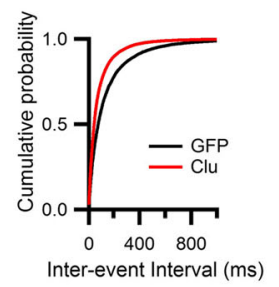

D

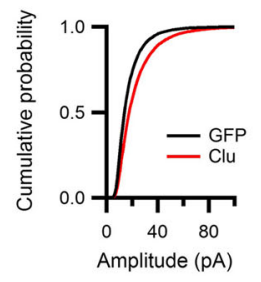

B

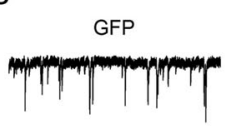

Clu

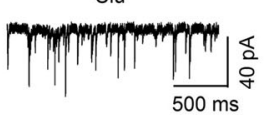

E

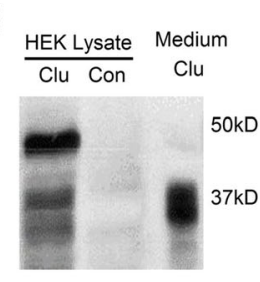

G

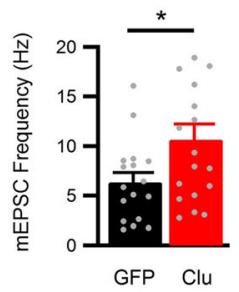

F

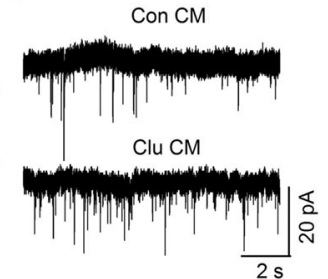

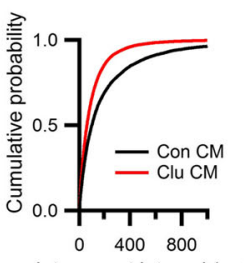

Inter-event Interval (ms)

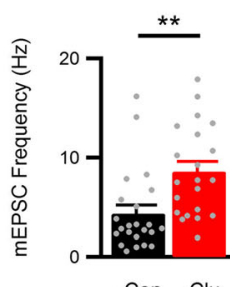

Con Clu

$\mathrm{H}$
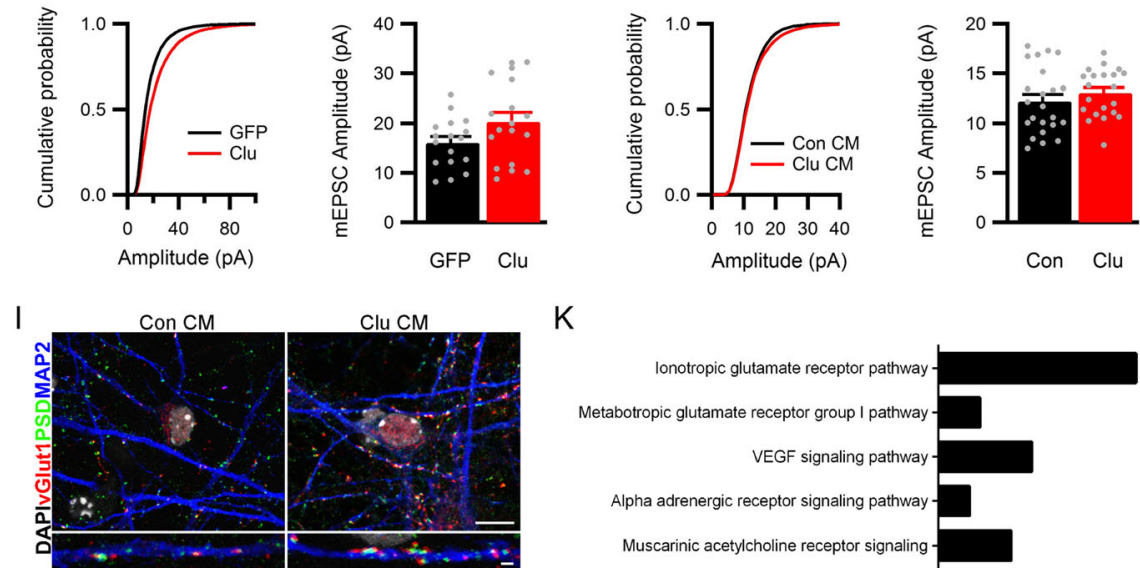

K

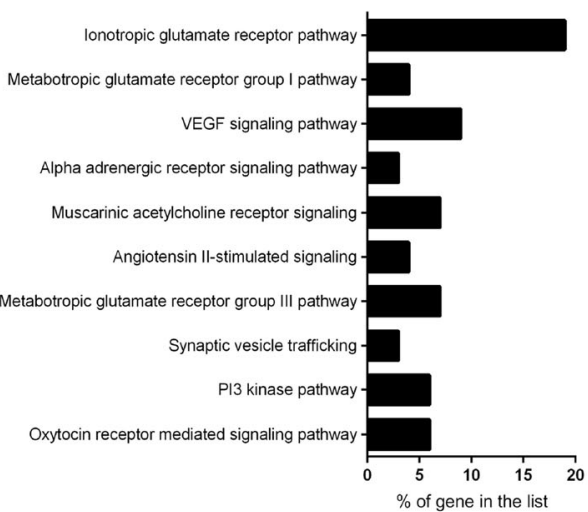

Fig. 4 Secreted Clu promotes excitatory synaptic function in vitro. a Western blotting of Clu in conditioned medium of primary astrocyte infected with AAV-GFAP-GFP (GFP) or AAV-GFAP-Clu (Clu) at 9 or 12 days post infection (d.p.i.). b mEPSC sample traces from primary neurons co-cultured with primary astrocytes infected with AAV-GFAP-GFP or AAV-GFAP-Clu at 12-13 DIV (scale bar, 40 pA/500 ms). c Cumulative distribution of interevent interval from all mEPSCs events of 17 neurons co-cultured with GFP astrocytes and 18 neurons co-cultured with Clu astrocytes (left) and average mEPSC frequency (right). d Cumulative distribution of amplitude (left) and average amplitude (right) in neurons co-cultured with GFP ( $n=17)$ or Clu $(n=18)$ astrocytes. e Western blot analysis of Clu in lysate of HEK293 cells transfected with Clu or vector control (Con) plasmid and in conditioned medium of Clu-transfect HEK293 cells. f mEPSC sample traces from primary cultured neurons treated with control conditioned medium (Con CM) or Clu CM at 14-16 DIV (scale bar, 20 pA/2 s). g Cumulative distribution of inter-event interval from all mEPSCs events of 23 neurons treated with Con CM and 21 neurons treated with Clu CM (left) and average mEPSC frequency (right). $\mathbf{h}$ Cumulative distribution of amplitude (left) and average amplitude (right) in neurons treated with Con CM $(n=23)$ or Clu CM $(n=21)$. i Representative Confocal images of cultured neurons triple-stained with anti-vGlut1, -PSD95 and -MAP2 antibodies and counterstained with DAPI. Lower panel is a zoomed-in view of a dendritic segment. Colocalized pre- (vGluT1) and post-synaptic (PSD95) puncta reveal sites of excitatory synapses. Scale bar, $10 \mu \mathrm{m}$ (top), $1 \mu \mathrm{m}$ (bottom). $\mathbf{j}$ quantification of synaptic density. $\mathbf{k}$ Gene Ontology analysis of upregulated genes in Clu vs. control CM treated neuronal cultures. All data are presented as mean \pm SEM. ${ }^{*} p<0.05 ; * * p<0.01 ; * * * p<0.001$ (Student's t test) 
A

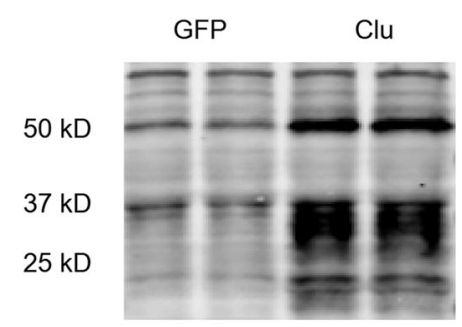

Tub

B

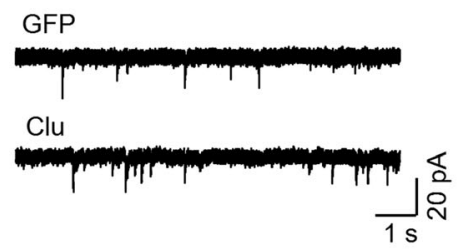

C
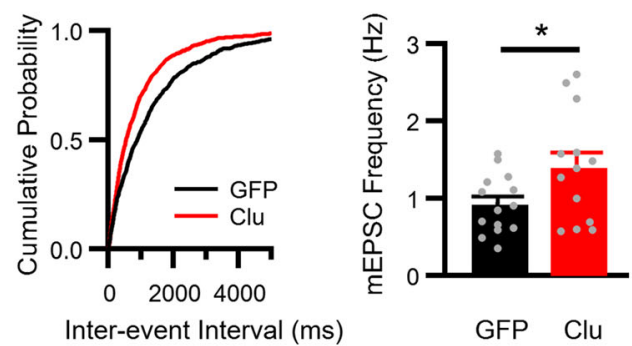

D

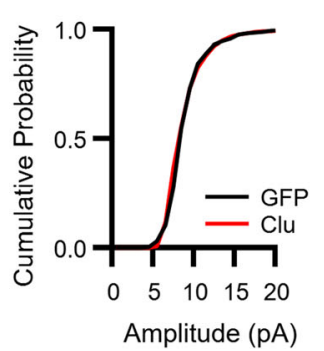

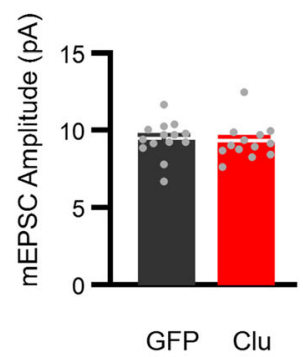

Fig. 5 Astrocytic Clu overexpression promotes excitatory synaptic transmission in vivo. a Western blotting of Clu expression in hippocampal tissues of wild-type mice injected with AAV-GFAP-GFP or AAV-GFAP-Clu. Tubulin (Tub) was used as a loading control. b mEPSC sample traces from hippocampal CA1 pyramidal neurons of GFP or Clu transduced mice (scale bar, 20 pA/1 s). c Cumulative distribution of inter-event interval from all mEPSCs events of 14 neurons in mice injected with AAV-GFAP-GFP and 13 neurons injected with AAV-GFAP-Clu (left) and average mEPSC frequency (right). $\mathbf{d}$ Cumulative distribution of amplitude (left) and average mEPSC amplitude (right) of neurons infected with GFP ( $n=14$ ) or Clu $(n=13)$ viruses. Number of animals tested: $N=3$ per group. Data presented are mean \pm SEM. ${ }^{*} p<0.05$ (Student's $t$ test)

GFP mice and analyzed the number of dendritic spines in Thy1-GFP-labeled CA 1 pyramidal neurons (Fig. 6e). We found that the densities of total spines and spine sub-types in apical dendrites were both increased in AAV-GFAP-Clu injected $\mathrm{KO}$ mice compared to GFP injected controls (Fig. $6 f$ \& g). Indeed, the total spine density in AAV-GFAP-Clu injected Clu KO mice was comparable with that of the WT mice (compare Fig. $6 \mathrm{f}$ $\mathrm{KO}$;Clu with Fig. 3b WT). Thus, astrocytic expression of Clu is sufficient to rescue the synaptic deficits present in global $\mathrm{Clu}$ knockout mice.

\section{Astrocytic Clu overexpression ameliorates AD neuropathology and rescues synaptic deficits in 5XFAD mice}

Having established a physiological function of astrocytic $\mathrm{Clu}$ in promoting synaptic structure and excitatory synaptic transmission, we next investigated how Clu upregulation impacts synaptic properties and neuropathology relevant to $\mathrm{AD}$. We chose the $5 \mathrm{XFAD}$ mice that exhibit aggressive amyloid deposition and synaptic deficits detectable at 4 months of age [31]. Consistent with previous reports [36], we observed an increased expression of $\mathrm{Clu}$ in 5XFAD animals (Fig. S2). Besides astrocytes, Clu immunoreactivity can be found associated with amyloid plaques as well as in vessels of cerebral amyloid angiopathy (Fig. S3). Prominent astroglial Clu overexpression with characteristic diffuse patterns can be detected in both the cortex and hippocampus of 5XFAD mice injected with AAV-GFAP-Clu (Fig. S4). We first evaluated the effect of Clu overexpression on $A \beta$ pathology. Only female mice were used to reduce gender-based variabilities. Staining of brain sections of 4 month-old 5XFAD mice injected with GFP or Clu viruses with methoxy-X04, which recognizes $\beta$-sheet conformation, and $6 \mathrm{E} 10$, which identifies diffused and aggregated $A \beta$, both showed that Clu overexpression markedly reduced the total coverage and the number of amyloid deposits without affecting the size of the plaques in the cortex (Fig. 7a \& b) and hippocampus (Fig. S5) of 5XFAD mice. This is associated with reduced glial relativities visualized by Iba1, GFAP and CD68 immunoreactivities (Fig. 7c \& d), as well as the dystrophic neurites detected by Lamp1 immunostaining (Fig. 7e \& f).

Lastly, we investigated whether astrocytic Clu overexpression could rescue the synaptic impairment previously reported in 5XFAD mice [37]. We recorded mEPSCs of CA1 pyramidal neurons of brain slices of 4 month-old WT and 5X FAD mice injected with AAVGFAP-GFP or AAV-GFAP-Clu (Fig. 8). We observed significant decreases in mEPSC frequency in neurons from 5X FAD brains compared with WT controls (Fig. 8b). In contrast, mEPSC amplitude was comparable among all groups (Fig. 8c). Strikingly, Clu overexpression 

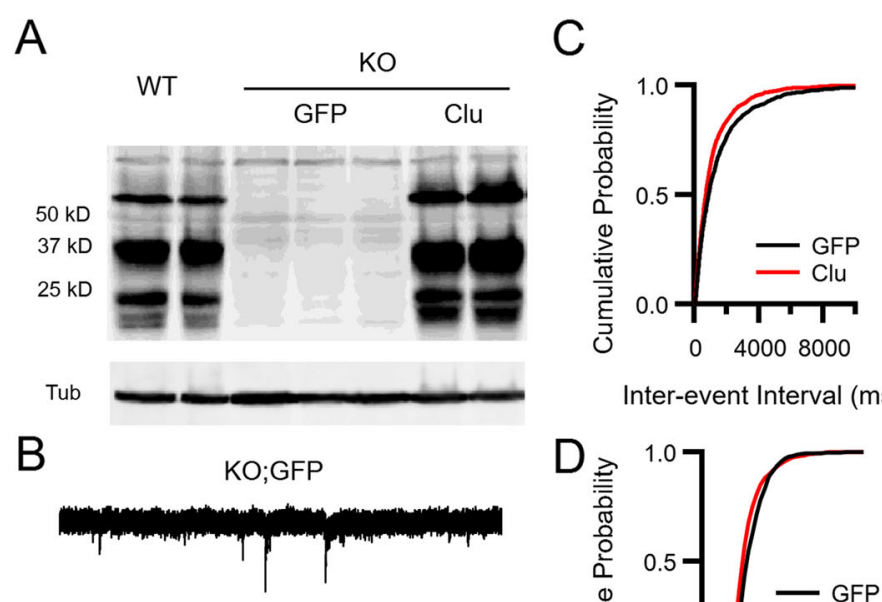

Inter-event Interval (ms)
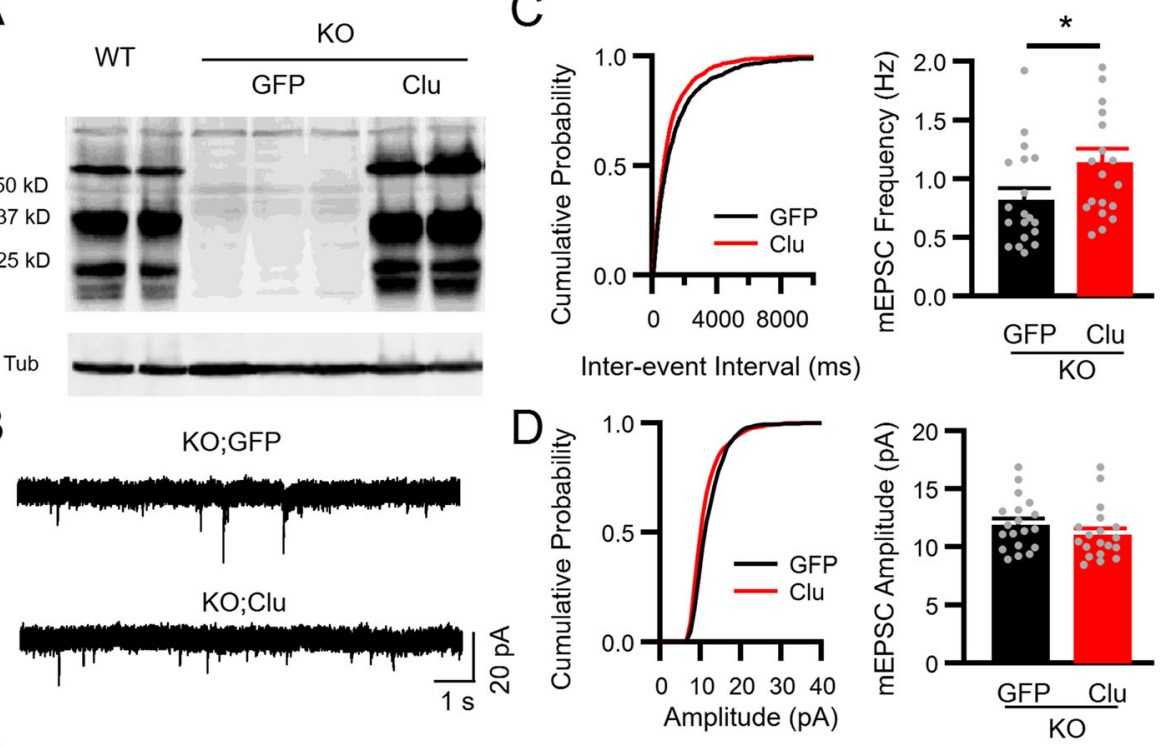

$E$

KO;GFP

$\mathrm{KO} ; \mathrm{Clu}$

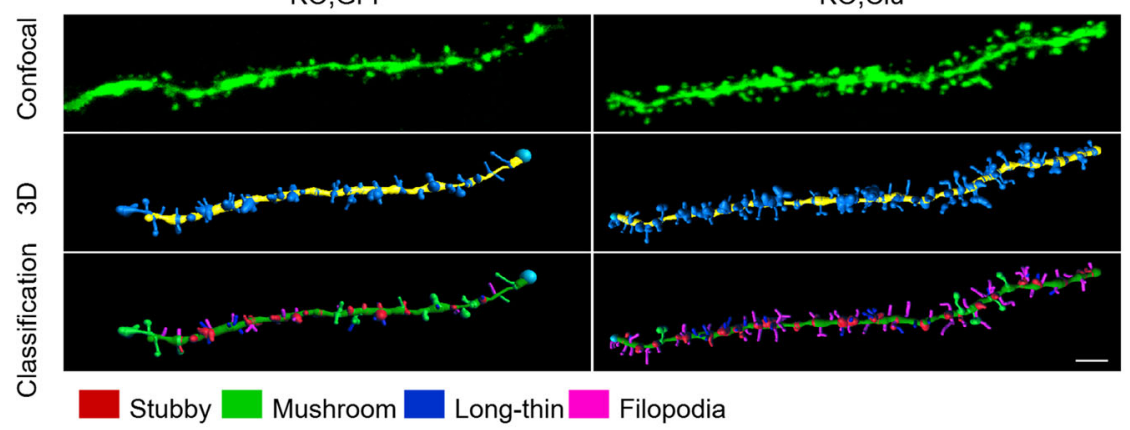

$\mathrm{F}$

G

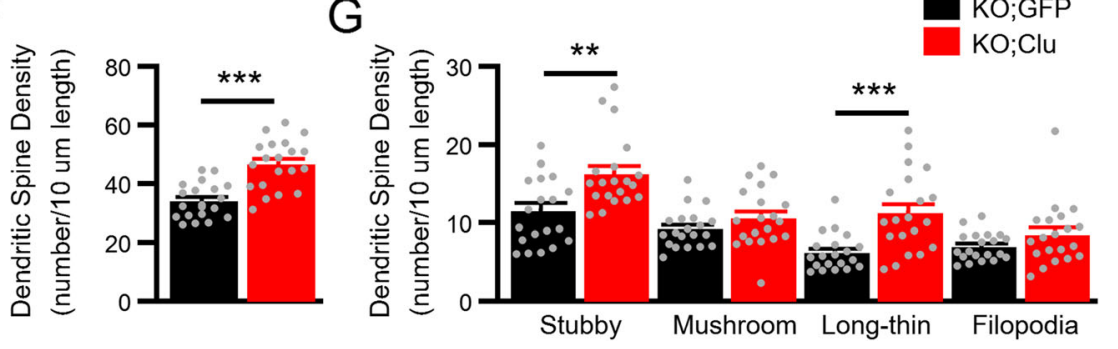

Fig. 6 Astrocytic expression of Clu rescues synaptic deficit in Clu KO mice. a Western blotting of Clu expression in hippocampal tissues of WT and Clu KO mice injected with AAV-GFAP-GFP or AAV-GFAP-Clu. Tub: Tubulin loading control. b mEPSC sample traces from hippocampal CA1 pyramidal neurons of KO mice injected with AAV-GFAP-GFP (KO;GFP) or AAV-GFAP-Clu (KO;Clu). Scale bar, 20 pA/1 s. c Cumulative distribution of inter-event interval (left) from all mEPSCs events of 19 neurons in KO mice each injected with AAV-GFAP-GFP or AAV-GFAP-Clu. d Cumulative distribution of amplitude (left) and average mEPSC amplitude of KO neurons infected with GFP or Clu viruses ( $n=19$ each). e Representative dendritic spines of Thy1-GFP-labeled dendrites of area CA1 of hippocampal pyramidal neurons of four-month-old Clu KO injected with AAVGFAP-GFP (KO;GFP) or AAV-GFAP-Clu (KO;Clu). IMARIS softward was used to reconstruct the 3D rendering of the spines on dendrites based on confocal images of GFP-positive neurons and to classify the four spine types (mushroom, stubby, long-thin, and filopodia). Scale bar, $2 \mu \mathrm{m}$. $\mathbf{f}$ Total spine density in $\mathrm{KO} ; \mathrm{GFP}$ and $\mathrm{KO} ; \mathrm{Clu}$ mouse brains. $\mathbf{g}$ Density of each of the four spine types in secondary apical dendrites. Dendritic segments were derived from 5 random neurons per mouse/ 4 animals for each group. Number of animals tested for mEPSCs: $N=3$ per group. All data are presented as mean \pm SEM. ${ }^{*} p<0.05 ; * * p<0.01 ; * * * p<0.001$ (Student's t test)

in 5X FAD mice restored the mEPSC frequency to WT levels (Fig. 8b, WT GFP vs. 5xFAD Clu, not significant), demonstrating a complete rescue of presynaptic dysfunction of 5X FAD mice by Clu overexpression. Given that
$\mathrm{A} \beta$ pathology is only partially attenuated, the results suggest that the complete rescue of synaptic function by astrocytic $\mathrm{Clu}$ is due to its combined effects in synapse enhancement and $A \beta$ antagonism. 
A

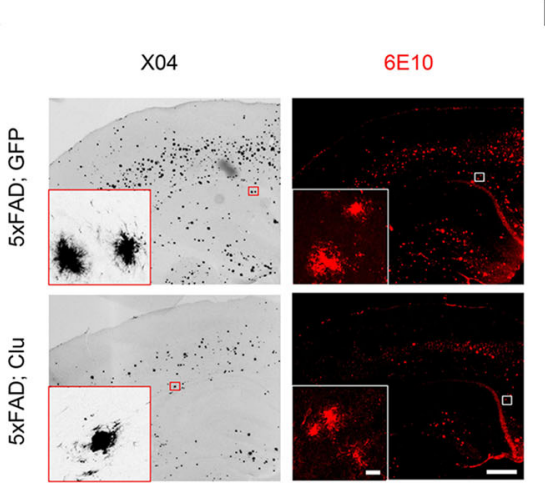

C

GFAP
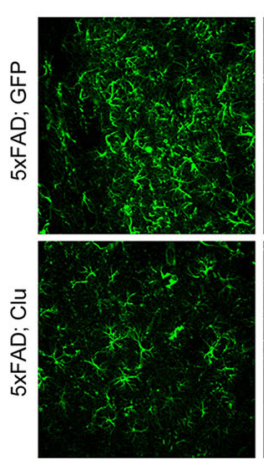

D

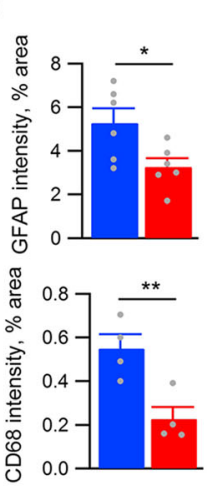

Iba-1

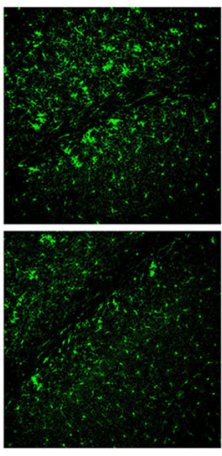

E

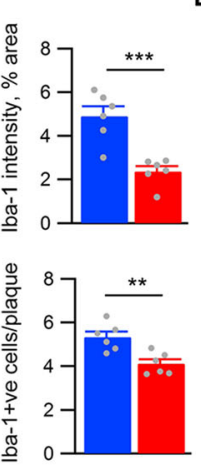

B $\square$ 5×FAD; GFP
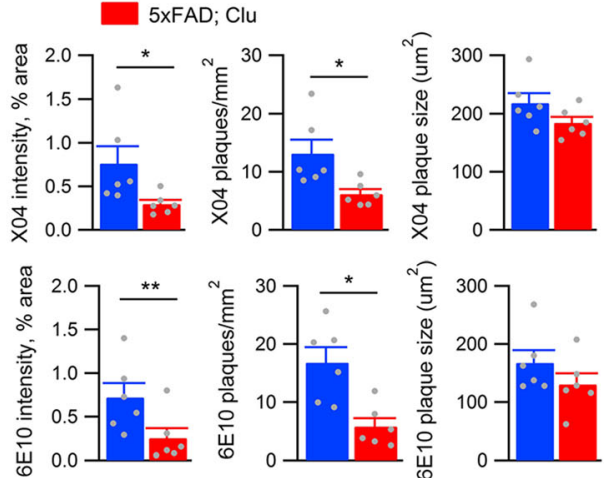

CD68

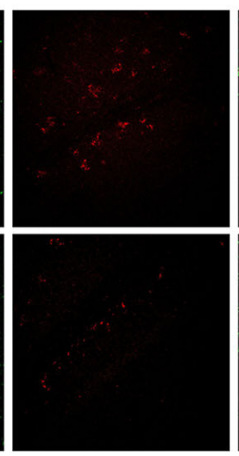

Lamp1
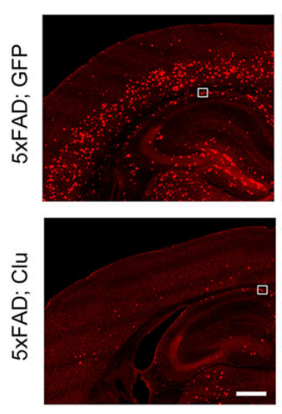

X04/lba-1/CD68

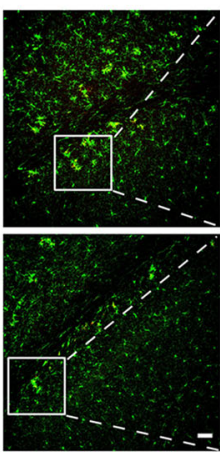

X04//ba-1/CD68

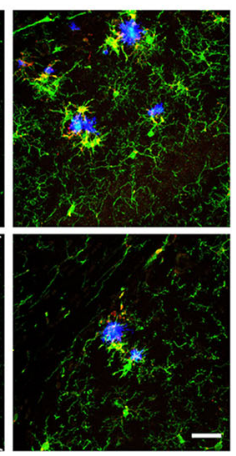

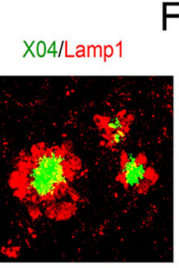

$F$

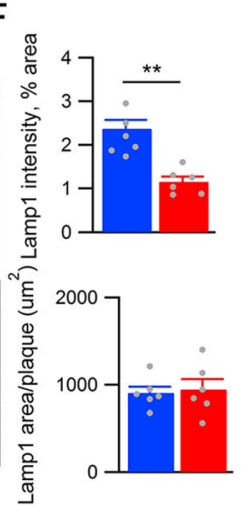

Fig. 7 Astrocytic Clu overexpression ameliorates amyloid pathology and glial reactivity in 5xFAD mice. a Representative images of methoxy-X04 and 6 E10 staining of 5XFAD mouse brains injected with GFP or Clu. Scale bar, $500 \mu \mathrm{m}$ (insert $50 \mu \mathrm{m}$ ). b Quantification of X04 or 6E10 intensities, plaque numbers and plaque size. c Representative immunofluorescence images using anti-GFAP, -Iba-1 and -CD68 antibodies. Scale bar, $50 \mu \mathrm{m}$. $\mathbf{d}$ Quantification of immunointensitivites. e Representative anti-Lamp1 immunofluorescence images. $\mathbf{f}$ Quantification of Lamp1 immunoreactivities. $n=6$ /group. Scale bar, $500 \mu \mathrm{m}$, second from right; $50 \mu \mathrm{m}$, right for both (c) \& (e). All data are presented as mean \pm SEM. ${ }^{*} p<0.05 ; * * p<0.01$; $* * * p<0.001$ (Student's t test)

\section{Discussion}

Clusterin is a well-established genetic modifier for LOAD. Since both risk and protective alleles have been identified which may be associated with its expression levels, loss- and gain-of-function studies of Clu may both reveal important insights into its genetic underpinning. Using Clu deficient mice and by AAV-mediated Clu expression in astrocytes, we reveal here that Clu secreted from astrocyte is co-localized to the presynaptic site of excitatory neurons where it modulates excitatory synaptic transmission and spine density. Astroglial Clu expression is sufficient to rescue the impaired synaptic structure and function in $\mathrm{Clu}$ knockout mice and led to the attenuation of amyloid pathology and synaptic deficit in 5XFAD mice.

Astrocytes are increasingly recognized to play critical roles in synapse formation and synaptic function through their physical proximity with neurons and by 
A

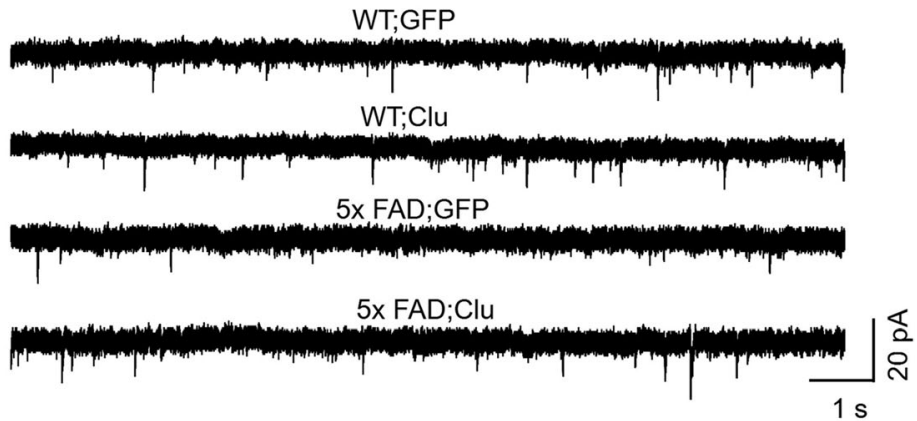

B
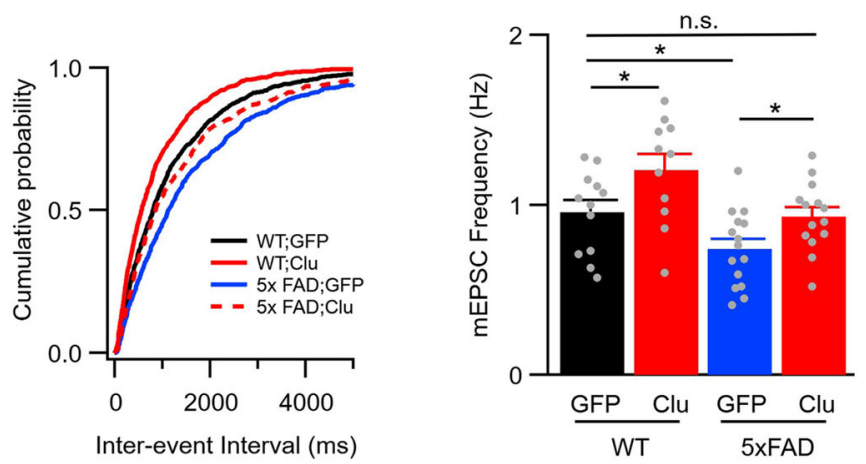

C
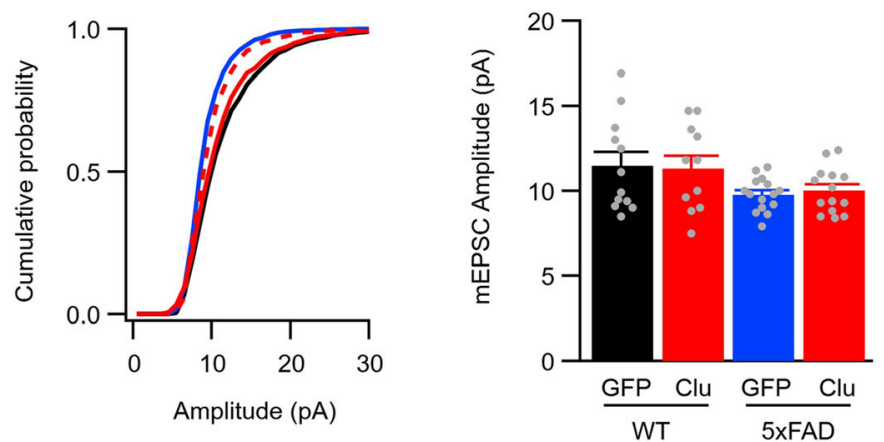

Fig. 8 Astrocytic Clu expression rescues synaptic dysfunction in 5xFAD mice. a mEPSC sample traces from hippocampal CA1 pyramidal neurons of WT and 5xFAD mice injected with AAV-GFAP-GFP or AAV-GFAP-Clu (scale bar, 20 pA/1 s). b Cumulative distribution of inter-event interval from all mEPSCs events (left) and average mEPSC frequency (right) ( $n=12 \mathrm{WT} ; \mathrm{GFP} ; n=15 \mathrm{WT} ; \mathrm{Clu} ; n=11$ 5xFAD; GFP; $n=14$ 5xFAD; Clu). c Cumulative distribution of amplitude (left) and average mEPSC amplitude (right) ( $n=12 \mathrm{WT}$; GFP; $n=15 \mathrm{WT} ; \mathrm{Clu} ; n=115 \times \mathrm{FAD} ; \mathrm{GFP} ; n=14$ 5XFAD; Clu). Number of animals tested: $N=3$ per group. Data presented are mean $\pm \mathrm{SEM}$. ${ }^{*} p<0.05 ; \mathrm{n} . \mathrm{s}$. not significant $(p>0.05)$ (Two-way ANOVA)

secreting synaptotrophic factors [38]. For example, astrocytes secrete thrombospondins to promote synaptogenesis [39, 40], hevin and SPARC to control synapse formation [41], and glypican 4 and 6 to induce functional synapses [42]. In addition to these synaptogenic factors, several other molecules including transforming growth factor $\beta$ [43], D-Serine [44] and cholesterol associated with apolipoprotein E (ApoE) [45] have been identified as astrocyte derived factors that regulate specific steps of synapse formation via interaction with neuronal receptors. We present evidence that $\mathrm{Clu}$ acts as an astrocyte secreted factor facilitating synapse formation and excitatory synaptic transmission. Specifically, endogenous $\mathrm{Clu}$ is predominantly expressed in astrocytes but is also localized close to the synaptic sites of excitatory neurons. Expression of $\mathrm{Clu}$ in sparse astrocytes of $\mathrm{Clu}$ knockout mice revealed the presence of $\mathrm{Clu}$ in both astrocyte cell body and fine distal processes in close proximity to vGlut1-marked synaptic puncta where it may be released. Loss of Clu results in impaired glutamatergic synaptic transmission and reduced dendritic spine density, and these phenotypes can be rescued by 
astrocytic expression of $\mathrm{Clu}$. We show that Clu promotes excitatory but not inhibitory synaptic transmission. This is likely attributed by its selective association with glutamatergic presynaptic marker vGlut1. The reason for this specificity and whether this is mediated by a direct interaction between Clu and vGlut1 or through other interacting proteins are not clear. In this regard, several putative Clu receptors have been reported including low-density lipoprotein receptor related protein 2 (LRP2) [46, 47], LRP8 [48], very low-density lipoprotein receptor [48], Plexin A4 [49], and triggering receptor expressed on myeloid cells 2 (TREM2) [50]. Whether these receptors are involved in mediating the synaptic localization and function of Clu remain to be investigated. Interestingly, a recent report demonstrated a role of TREM2 signaling in synapse sculpting [51]. Using live-cell imaging, a separate study revealed that microglia frequently engulf presynaptic, but not postsynaptic, site whereby participating synaptic remodeling and maintenance [52]. Thus it is tempting to speculate that the presynaptic function of Clu may involve microglia and CluTREM2 interaction.

We report here that astrocytic Clu overexpression leads to a drastic reduction of parenchymal $A \beta$ pathology and associated glial reactivity and dystrophic neurite accumulation in 5XFAD model. This may be mediated by the following mechanisms, all involving Clu-A $\beta$ interactions. Firstly, as an extracellular chaperone, Clu has been shown to bind to $A \beta$ and affect its nucleation and aggregation $[25,53]$. Thus, astrocyte secreted Clu may block $A \beta$ deposition through this chaperone function. Secondly, Clu may promote $A \beta$ clearance through microglia uptake. Supporting this idea, lipidated Clu has been shown to complex with $A \beta$ and mediate $A \beta$ clearance through binding to microglia TREM2 [50, 54]. Additionally, a recent report demonstrates that $\mathrm{Clu}$ facilitates the degradation of its misfolded protein clients including $A \beta$ via heparan sulfate receptor-mediated endocytosis [55]. Lastly, Clu has been well-documented to complex with $A \beta$ and regulate $A \beta$ clearance through the perivascular drainage system at the blood brain barrier and/or the blood-cerebrospinal fluid barrier via LRP2 $[46,47,56]$. Thus, astrocytic Clu overexpression could drive this process and, by which means, remove parenchymal $A \beta$.

Studies of $\mathrm{Clu}$ knockout mice documented increased CAA in APP/PS1 transgenic mice, supporting a functional role of $\mathrm{Clu}$ in $\mathrm{A} \beta$ clearance through the vascular system [27]. However, this is associated with reduced parenchymal $\mathrm{A} \beta$ plaques, a finding that is not consistent with the anti-amyloidogenic properties of Clu we observed [26, 27]. Although the precise reason for the discrepancy is not clear, it may be attributed by the dynamic regulation of $\mathrm{Clu}$ in both $A \beta$ fibrillogenesis and clearance, making it difficult to directly compare and contrast the loss- and gain-of-function studies. In addition, the $\mathrm{A} \beta$ phenotypes presented in $\mathrm{Clu}$ null mice may be confounded by genetic redundancies since work done by DeMattos et al. clearly demonstrated an additive effect of ApoE and Clu in A $\beta$ metabolism [57].

Our results show that astroglial Clu expression completely rescued the presynaptic deficit in 5XFAD mice although the $A \beta$ pathology is only partially reduced, suggesting the $\mathrm{Clu}$ has a direct effect on $\mathrm{A} \beta$-induced synaptic toxicity independent of amyloid pathology. It is known that neuronal activity evokes the release of $A \beta$ at the synapse, leading to increased levels of extracellular $A \beta$ at or near synapses [58]. Abnormal assemblies of $A \beta$ suppress excitatory transmitter release [59]. It is possible that astrocyte-secreted and synaptically targeted $\mathrm{Clu}$ could improve synaptic transmission by mediating the clearance of this $A \beta$ pool and/or by interacting with vGlut1 and enhancing basal synaptic transmission.

Elevated levels of CLU have been observed in the brain and cerebrospinal fluid of AD patients [17-20]. Our findings that $\mathrm{Clu}$ overexpression suppresses $A \beta$ pathology and restores synaptic function support the idea that this increase serves as an adaptive mechanism to respond to ongoing neuronal insults and $A \beta$ stress, especially at early stages of $\mathrm{AD}$ pathogenesis. However, overwhelming accumulation of $A \beta$ may lead to its sequestration and reduced capacity for synaptic maintenance and $A \beta$ clearance. This assessment is consistent with genetic evidence that the protective allele of $C L U$ may be associated with increased expression and vice versa $[5-8]$.

\section{Conclusions}

Our study provides evidence for an essential role of $\mathrm{Clu}$ secreted from astrocyte in modulating excitatory synaptic function and amyloid pathogenesis. Elevating CLU levels in the brain may afford protection against $\mathrm{AD}$ by enhancing synaptic transmission and through $\mathrm{A} \beta$ reduction.

\section{Supplementary Information}

The online version contains supplementary material available at https://doi. org/10.1186/s13024-021-00426-7.

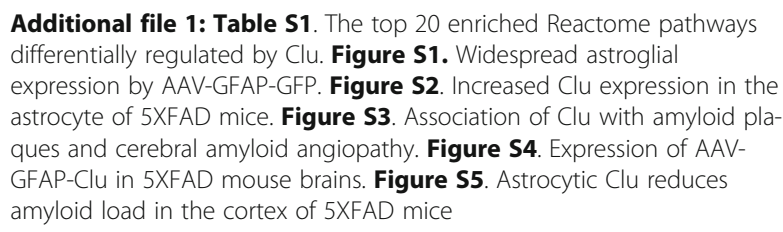

\section{Abbreviations}

AB: Amyloid beta; ACSF: Artificial cerebrospinal fluid; AD: Alzheimer's disease: ApoE: Apolipoprotein E; CAA: Cerebral amyloid angiopathy; Clu: Clusterin; 
CSF: Cerebrospinal fluid; CM: Conditioned medium; fEPSPs: field excitatory postsynaptic potentials; GFAP: Glial fibrillary acidic protein; GO: Gene ontology; KO: Knockout; LRP: lipoprotein receptor related protein; LOAD: Late-onset AD; mEPSCs: miniature excitatory postsynaptic currents; mIPSCs: miniature inhibitory postsynaptic currents; PANTHER: Protein Analysis Through Evolutionary Relationships; PBS: Phosphate-buffered saline; PDL: Poly-D-lysine; PFA: Paraformaldehyde; PPR: Paired-pulse ratio; TREM2: Triggering receptor expressed on myeloid cells 2; vGlut1: vesicular glutamate transporter 1 ; WT: Wild-type

\section{Acknowledgments}

We thank B. Deneen for providing the Aldh1L1-GFP mice and the Gene Vector Core of Baylor College of Medicine for AAV preparations. We are grateful to N. Aithmitti and B. Contreras for expert technical support and members of the Zheng laboratory for stimulating discussions.

\section{Authors' contributions}

$\mathrm{FC}, \mathrm{BW}$ and $\mathrm{HZ}$ conceived of the project and designed the experiments. $\mathrm{FC}$, DBS, AG and BW performed the experiments and data analysis. JDF provided reagents and $\mathrm{Clu}$ knockout mice. BW, FC and $\mathrm{HZ}$ wrote the manuscript. All authors read and approved the manuscript.

\section{Funding}

This study was supported by grants from the NIH (RF1 AG054111, R01 NS093652, R01 AG020670, R01 AG057509, and RF1 AG062257 to HZ).

\section{Availability of data and materials}

The datasets used and/or analyzed during the current study are available from the corresponding author on reasonable request.

\section{Ethics approval and consent to participate}

Approval from the Institutional Animal Care and Use Committee of Baylor College of Medicine was obtained prior to all animal-related studies (IACUC protocol \# AN-1853).

\section{Consent for publication}

All authors have approved the contents of this manuscript and provided consent for publication.

\section{Competing interests}

The authors declare that they have no competing interests.

\section{Author details}

'Huffington Center on Aging, Baylor College of Medicine, Houston, TX 77030, USA. ${ }^{2}$ Present address: Stanley Center for Psychiatric Research, Broad Institute of MIT and Harvard, Cambridge, MA 02142, USA. ${ }^{3}$ Department of Neuroscience, Mayo Clinic, Scottsdale, AZ 85259, USA. "Department of Molecular and Human Genetics, Baylor College of Medicine, Houston, TX 77030, USA.

\section{Received: 24 September 2020 Accepted: 14 January 2021}

Published online: 31 January 2021

\section{References}

1. Selkoe DJ. Alzheimer's disease is a synaptic failure. Science (New York, NY). 2002;298:789-91.

2. Tanzi RE, Bertram L. Twenty years of the Alzheimer's disease amyloid hypothesis: a genetic perspective. Cell. 2005;120:545-55.

3. Harold D, Abraham R, Hollingworth P, Sims R, Gerrish A, Hamshere ML, Pahwa JS, Moskvina V, Dowzell K, Williams A, et al. Genome-wide association study identifies variants at CLU and PICALM associated with Alzheimer's disease. Nat Genet. 2009;41:1088-93.

4. Lambert JC, Heath S, Even G, Campion D, Sleegers K, Hiltunen M, Combarros O, Zelenika D, Bullido MJ, Tavernier B, et al. Genome-wide association study identifies variants at CLU and CR1 associated with Alzheimer's disease. Nat Genet. 2009:41:1094-9.

5. Roussotte FF, Gutman BA, Madsen SK, Colby JB, Thompson PM. Combined effects of Alzheimer risk variants in the CLU and ApoE genes on ventricular expansion patterns in the elderly. J Neurosci. 2014;34:6537-45.

6. Ling IF, Bhongsatiern J, Simpson JF, Fardo DW, Estus S. Genetics of clusterin isoform expression and Alzheimer's disease risk. PLoS One. 2012;7:e33923.
7. Tan L, Wang HF, Tan MS, Tan CC, Zhu XC, Miao D, Yu WJ, Jiang T, Tan L, Yu $J$ T. Effect of CLU genetic variants on cerebrospinal fluid and neuroimaging markers in healthy, mild cognitive impairment and Alzheimer's disease cohorts. Sci Rep. 2016;6:26027.

8. Allen M, Zou F, Chai HS, Younkin CS, Crook J, Pankratz VS, Carrasquillo MM, Rowley CN, Nair AA, Middha S, et al. Novel late-onset Alzheimer disease loci variants associate with brain gene expression. Neurology. 2012;79:221-8.

9. Thambisetty M, Beason-Held LL, An Y, Kraut M, Nalls M, Hernandez DG, Singleton $A B$, Zonderman AB, Ferrucci L, Lovestone S, Resnick SM. Alzheimer risk variant CLU and brain function during aging. Biol Psychiatry. 2013;73:399-405.

10. Pedraza O, Allen M, Jennette K, Carrasquillo M, Crook J, Serie D, Pankratz VS, Palusak R, Nguyen T, Malphrus K, et al. Evaluation of memory endophenotypes for association with CLU, CR1, and PICALM variants in black and white subjects. Alzheimers Dement. 2014;10:205-13.

11. Braskie MN, Jahanshad N, Stein $J$, Barysheva M, McMahon $K L$, de Zubicaray Gl, Martin NG, Wright MJ, Ringman JM, Toga AW, Thompson PM. Common Alzheimer's disease risk variant within the CLU gene affects white matter microstructure in young adults. J Neurosci. 2011;31:6764-70.

12. Lancaster TM, Brindley LM, Tansey KE, Sims RC, Mantripragada K, Owen MJ, Williams J, Linden DE. Alzheimer's disease risk variant in CLU is associated with neural inefficiency in healthy individuals. Alzheimers Dement. 2015;11:1144-52.

13. Calero M, Tokuda T, Rostagno A, Kumar A, Zlokovic B, Frangione B, Ghiso J. Functional and structural properties of lipid-associated apolipoprotein J (clusterin). Biochem J. 1999:344(Pt 2):375-83.

14. Humphreys DT, Carver JA, Easterbrook-Smith SB, Wilson MR. Clusterin has chaperone-like activity similar to that of small heat shock proteins. J Biol Chem. 1999;274:6875-81.

15. Jenne DE, Tschopp J. Molecular structure and functional characterization of a human complement cytolysis inhibitor found in blood and seminal plasma: identity to sulfated glycoprotein 2, a constituent of rat testis fluid. Proc Natl Acad Sci U S A. 1989;86:7123-7.

16. Foster EM, Dangla-Valls A, Lovestone S, Ribe EM, Buckley NJ. Clusterin in Alzheimer's disease: mechanisms, genetics, and lessons from other pathologies. Front Neurosci. 2019;13:164.

17. Bertrand P, Poirier J, Oda T, Finch CE, Pasinetti GM. Association of apolipoprotein E genotype with brain levels of apolipoprotein E and apolipoprotein J (clusterin) in Alzheimer disease. Brain Res Mol Brain Res. 1995;33:174-8.

18. Lidstrom AM, Bogdanovic N, Hesse C, Volkman I, Davidsson P, Blennow K Clusterin (apolipoprotein J) protein levels are increased in hippocampus and in frontal cortex in Alzheimer's disease. Exp Neurol. 1998;154:511-21.

19. May PC, Lampert-Etchells M, Johnson SA, Poirier J, Masters JN, Finch CE. Dynamics of gene expression for a hippocampal glycoprotein elevated in Alzheimer's disease and in response to experimental lesions in rat. Neuron. 1990;5:831-9.

20. Miners JS, Clarke P, Love S. Clusterin levels are increased in Alzheimer's disease and influence the regional distribution of $A \beta$. Brain Pathol (Zurich, Switzerland). 2017;27:305-13.

21. Kida E, Choi-Miura NH, Wisniewski KE. Deposition of apolipoproteins E and J in senile plaques is topographically determined in both Alzheimer's disease and Down's syndrome brain. Brain Res. 1995;685:211-6.

22. Camacho J, Moline T, Bonaterra-Pastra A, Ramon YCS, Martinez-Saez E, Hernandez-Guillamon M. Brain ApoA-I, ApoJ and ApoE Immunodetection in Cerebral Amyloid Angiopathy. Front Neurol. 2019;10:187.

23. McGeer PL, Kawamata T, Walker DG. Distribution of clusterin in Alzheimer brain tissue. Brain Res. 1992;579:337-41.

24. Wilson MR, Easterbrook-Smith SB. Clusterin is a secreted mammalian chaperone. Trends Biochem Sci. 2000;25:95-8.

25. Narayan P, Orte A, Clarke RW, Bolognesi B, Hook S, Ganzinger KA, Meehan S, Wilson MR, Dobson CM, Klenerman D. The extracellular chaperone clusterin sequesters oligomeric forms of the amyloid-beta(1-40) peptide. Nat Struct Mol Biol. 2011;19:79-83.

26. DeMattos RB, O'Dell MA, Parsadanian M, Taylor JW, Harmony JA, Bales KR, Paul SM, Aronow BJ, Holtzman DM. Clusterin promotes amyloid plaque formation and is critical for neuritic toxicity in a mouse model of Alzheimer's disease. Proc Natl Acad Sci U S A. 2002;99:10843-8.

27. Wojtas AM, Kang SS, Olley BM, Gatherer M, Shinohara M, Lozano PA, Liu CC, Kurti A, Baker KE, Dickson DW, et al. Loss of clusterin shifts amyloid deposition to the cerebrovasculature via disruption of perivascular drainage pathways. Proc Natl Acad Sci U S A. 2017;114:E6962-e6971. 
28. John Lin CC, Yu K, Hatcher A, Huang TW, Lee HK, Carlson J, Weston MC, Chen F, Zhang Y, Zhu W, et al. Identification of diverse astrocyte populations and their malignant analogs. Nat Neurosci. 2017;20:396-405.

29. McLaughlin L, Zhu G, Mistry M, Ley-Ebert C, Stuart WD, Florio CJ, Groen PA, Witt SA, Kimball TR, Witte DP, et al. Apolipoprotein J/clusterin limits the severity of murine autoimmune myocarditis. J Clin Invest. 2000;106:1105-13.

30. Feng G, Mellor RH, Bernstein M, Keller-Peck C, Nguyen QT, Wallace M, Nerbonne JM, Lichtman JW, Sanes JR. Imaging neuronal subsets in transgenic mice expressing multiple spectral variants of GFP. Neuron. 2000; 28:41-51.

31. Oakley H, Cole SL, Logan S, Maus E, Shao P, Craft J, Guillozet-Bongaarts A, Ohno M, Disterhoft J, Van Eldik L, et al. Intraneuronal beta-amyloid aggregates, neurodegeneration, and neuron loss in transgenic mice with five familial Alzheimer's disease mutations: potential factors in amyloid plaque formation. J Neurosci. 2006;26:10129-40.

32. Pasinetti GM, Johnson SA, Oda T, Rozovsky I, Finch CE. Clusterin (SGP-2): a multifunctional glycoprotein with regional expression in astrocytes and neurons of the adult rat brain. J Comp Neurol. 1994;339:387-400.

33. DeMattos RB, Brendza RP, Heuser JE, Kierson M, Cirrito JR, Fryer J, Sullivan PM, Fagan AM, Han X, Holtzman DM. Purification and characterization of astrocyte-secreted apolipoprotein $\mathrm{E}$ and J-containing lipoproteins from wild-type and human apoE transgenic mice. Neurochem Int. 2001;39:41525.

34. Chakrabarty P, Rosario A, Cruz P, Siemienski Z, Ceballos-Diaz C, Crosby K, Jansen K, Borchelt DR, Kim JY, Jankowsky JL, et al. Capsid serotype and timing of injection determines AAV transduction in the neonatal mice brain. PLoS One. 2013;8:e67680

35. Martini-Stoica H, Cole AL, Swartzlander DB, Chen F, Wan YW, Bajaj L, Bader DA, Lee VMY, Trojanowski JQ, Liu Z, et al. TFEB enhances astroglial uptake of extracellular tau species and reduces tau spreading. J Exp Med. 2018;215: 2355-77.

36. Hong I, Kang T, Yoo Y, Park R, Lee J, Lee S, Kim J, Song B, Kim SY, Moon M, et al. Quantitative proteomic analysis of the hippocampus in the 5XFAD mouse model at early stages of Alzheimer's disease pathology. J Alzheimers Dis. 2013;36:321-34.

37. Buskila Y, Crowe SE, Ellis-Davies GC. Synaptic deficits in layer 5 neurons precede overt structural decay in 5xFAD mice. Neuroscience. 2013;254:1529.

38. Araque A, Carmignoto G, Haydon PG, Oliet SH, Robitaille R, Volterra A. Gliotransmitters travel in time and space. Neuron. 2014;81:728-39.

39. Christopherson KS, Ullian EM, Stokes CC, Mullowney CE, Hell JW, Agah A, Lawler J, Mosher DF, Bornstein P, Barres BA. Thrombospondins are astrocyte-secreted proteins that promote CNS synaptogenesis. Cell. 2005; 120:421-33.

40. Eroglu C, Allen NJ, Susman MW, O'Rourke NA, Park CY, Ozkan E, Chakraborty C, Mulinyawe SB, Annis DS, Huberman AD, et al. Gabapentin receptor alpha2delta-1 is a neuronal thrombospondin receptor responsible for excitatory CNS synaptogenesis. Cell. 2009;139:380-92.

41. Singh SK, Stogsdill JA, Pulimood NS, Dingsdale H, Kim YH, Pilaz LJ, Kim IH, Manhaes AC, Rodrigues WS Jr, Pamukcu A, et al. Astrocytes assemble Thalamocortical synapses by bridging NRX1a and NL1 via Hevin. Cell. 2016; 164:183-96.

42. Farhy-Tselnicker I, van Casteren ACM, Lee A, Chang VT, Aricescu AR, Allen NJ. Astrocyte-Secreted Glypican 4 Regulates Release of Neuronal Pentraxin 1 from Axons to Induce Functional Synapse Formation. Neuron. 2017;96:428445.e413.

43. Diniz LP, Almeida JC, Tortelli V, Vargas Lopes C, Setti-Perdigao P, Stipursky J, Kahn SA, Romao LF, de Miranda J, Alves-Leon SV, et al. Astrocyte-induced synaptogenesis is mediated by transforming growth factor beta signaling through modulation of D-serine levels in cerebral cortex neurons. J Biol Chem. 2012;287:41432-45.

44. Sultan S, Li L, Moss J, Petrelli F, Cassé F, Gebara E, Lopatar J, Pfrieger FW, Bezzi P, Bischofberger J, Toni N. Synaptic integration of adult-born hippocampal neurons is locally controlled by astrocytes. Neuron. 2015;88: 957-72.

45. Mauch DH, Nagler K, Schumacher S, Goritz C, Muller EC, Otto A, Pfrieger FW. CNS synaptogenesis promoted by glia-derived cholesterol. Science (New York, NY). 2001;294:1354-7.

46. Kounnas MZ, Loukinova EB, Stefansson S, Harmony JA, Brewer BH, Strickland DK, Argraves WS. Identification of glycoprotein 330 as an endocytic receptor for apolipoprotein J/clusterin. J Biol Chem. 1995;270:13070-5.
47. Zlokovic BV, Martel CL, Matsubara E, McComb JG, Zheng G, McCluskey RT, Frangione B, Ghiso J. Glycoprotein 330/megalin: probable role in receptormediated transport of apolipoprotein $\mathrm{J}$ alone and in a complex with Alzheimer disease amyloid beta at the blood-brain and blood-cerebrospinal fluid barriers. Proc Natl Acad Sci U S A. 1996;93:4229-34.

48. Leeb C, Eresheim C, Nimpf J. Clusterin is a ligand for apolipoprotein E receptor 2 (ApoER2) and very low density lipoprotein receptor (VLDLR) and signals via the Reelin-signaling pathway. J Biol Chem. 2014;289:4161-72.

49. Kang SS, Kurti A, Wojtas A, Baker KE, Liu CC, Kanekiyo T, Deming Y, Cruchaga C, Estus S, Bu G, Fryer JD. Identification of plexin A4 as a novel clusterin receptor links two Alzheimer's disease risk genes. Hum Mol Genet. 2016;25:3467-75.

50. Yeh FL, Wang Y, Tom I, Gonzalez LC, Sheng M. TREM2 binds to Apolipoproteins, including APOE and CLU/APOJ, and thereby facilitates uptake of amyloid-Beta by microglia. Neuron. 2016;91:328-40.

51. Filipello F, Morini R, Corradini I, Zerbi V, Canzi A, Michalski B, Erreni M, Markicevic M, Starvaggi-Cucuzza C, Otero K, et al. The Microglial Innate Immune Receptor TREM2 Is Required for Synapse Elimination and Normal Brain Connectivity. Immunity. 2018:48:979-991.e978.

52. Weinhard L, di Bartolomei G, Bolasco G, Machado P, Schieber NL, Neniskyte U, Exiga M, Vadisiute A, Raggioli A, Schertel A, et al. Microglia remodel synapses by presynaptic trogocytosis and spine head filopodia induction. Nat Commun. 2018;9:1228.

53. Beeg M, Stravalaci M, Romeo M, Carra AD, Cagnotto A, Rossi A, Diomede L, Salmona M, Gobbi M. Clusterin binds to Abeta1-42 oligomers with high affinity and interferes with peptide aggregation by inhibiting primary and secondary nucleation. J Biol Chem. 2016;291:6958-66.

54. Wang Y, Cella M, Mallinson K, Ulrich JD, Young KL, Robinette ML, Gilfillan S, Krishnan GM, Sudhakar S, Zinselmeyer BH, et al. TREM2 lipid sensing sustains the microglial response in an Alzheimer's disease model. Cell. 2015; 160:1061-71.

55. Itakura E, Chiba M, Murata T, Matsuura A. Heparan sulfate is a clearance receptor for aberrant extracellular proteins. J Cell Biol. 2020;219:e201911126.

56. Bell RD, Sagare AP, Friedman AE, Bedi GS, Holtzman DM, Deane R, Zlokovic BV. Transport pathways for clearance of human Alzheimer's amyloid betapeptide and apolipoproteins $\mathrm{E}$ and $\mathrm{J}$ in the mouse central nervous system. $J$ Cereb Blood Flow Metab. 2007;27:909-18.

57. DeMattos RB, Cirrito JR, Parsadanian M, May PC, O'Dell MA, Taylor JW, Harmony JA, Aronow BJ, Bales KR, Paul SM, Holtzman DM. ApoE and clusterin cooperatively suppress Abeta levels and deposition: evidence that ApoE regulates extracellular Abeta metabolism in vivo. Neuron. 2004;41: 193-202.

58. Kamenetz F, Tomita T, Hsieh H, Seabrook G, Borchelt D, Iwatsubo T, Sisodia S, Malinow R. APP processing and synaptic function. Neuron. 2003;37:92537.

59. He Y, Wei M, Wu Y, Qin H, Li W, Ma X, Cheng J, Ren J, Shen Y, Chen Z, et al. Amyloid $\beta$ oligomers suppress excitatory transmitter release via presynaptic depletion of phosphatidylinositol-4,5-bisphosphate. Nat Commun. 2019;10: 1193

\section{Publisher's Note}

Springer Nature remains neutral with regard to jurisdictional claims in published maps and institutional affiliations.

Ready to submit your research? Choose BMC and benefit from:

- fast, convenient online submission

- thorough peer review by experienced researchers in your field

- rapid publication on acceptance

- support for research data, including large and complex data types

- gold Open Access which fosters wider collaboration and increased citations

- maximum visibility for your research: over $100 \mathrm{M}$ website views per year

At $\mathrm{BMC}$, research is always in progress.

Learn more biomedcentral.com/submissions 